\title{
Control of Cavity Resonance Using Steady and Oscillatory Blowing
}

\author{
Alison M. Lamp and Ndaona Chokani \\ North Carolina State University, Raleigh, North Carolina
}

Prepared for NAG-1-1829

April 1999 


\begin{abstract}
An experimental study to investigate the effect of steady and oscillatory (with zero net mass flux) blowing on cavity resonance is undertaken. The objective is to study the basic mechanisms of the control of cavity resonance. An actuator is designed and calibrated to generate either steady blowing or oscillatory blowing with a zero net mass flux. The results of the experiment show that both steady and oscillatory blowing are effective, and reduce the amplitude of the dominant resonant mode by $10 \mathrm{~dB}$. The oscillatory blowing is however found to be more superior in that the same effectiveness could be accomplished with a momentum coefficient an order of magnitude smaller than for steady blowing. The experiment also confirms the results of previous computations that suggest the forcing frequency for oscillatory blowing must not be at harmonic frequencies of the cavity resonant modes.
\end{abstract}




\section{Acknowledgments}

This work was supported by NASA grant NAG-1-1829, monitored by Dr. R. D. Joslin, Flow Modeling and Control Branch, NASA Langley Research Center. The authors are grateful to R. L. Richardson of NC State for the making the actuator, and R. L. Clark and R. D. Harvey of NASA Langley for operating the Probe Calibration Tunnel. 


\section{List of Symbols}

$\begin{array}{ll}A_{j} & \text { Jet hole area } \\ A_{r} & \text { Cavity front wall area } \\ c_{\mu} & \text { Mean momentum coefficient } \\ <c_{\mu}> & \text { Fluctuating momentum coefficient } \\ f_{\mathrm{f}} & \text { Forcing frequency } \\ \mathrm{M}_{\infty} & \text { Free stream Mach number } \\ \mathrm{p}, & \text { Fluctuating pressure } \\ \mathrm{q} & \text { Free stream dynamic pressure } \\ \mathrm{Re} & \text { Reynolds number per meter } \\ \mathrm{SPL} & \text { Sound pressure level } \\ \mathrm{u} & \text { Mean velocity } \\ \mathrm{u}, & \text { Fluctuating velocity } \\ \rho & \text { Density in actuator delivery chamber }\end{array}$




\subsection{Introduction}

Cavity resonance occurs in a wide range of applications including in the wheel bays of commercial transports ${ }^{\prime}$. The wheel bays are a primary source of airframe noise due to the need to deploy the landing gear for the aircraft's low-speed approach and touchdown. The airframe noise levels may, during approach, even exceed the level of noise from the engine, and are thus a nuisance to the population living near airports. During the approach, the airframe noise is also the main source of the passenger cabin noise, as the noise is either radiated through the air to the cabin wall, or transmitted as vibrations through the aircraft's structure. Experimental studies ${ }^{2}$ have been conducted on full-scale aircraft and identify the wheel bays as one of the main sources of airframe noise. The spectrum-level increases may be $5-10 d B$. There is a need to reduce the noise levels associated with cavity flows in order that the proposed targets for increases in air-traffic may be met. This need has motivated experimental ${ }^{3-5}$ and computational ${ }^{6-10}$ studies directed towards improving our understanding of the nature of cavity flows, and to developing the means to suppress the cavity resonance. The cavity flows of interest are termed "open" type cavity flows, and generally occur for a cavity length-to-depth (L/D) ratio less than 10 . The cavity flow is then characterized by a number of time-varying phenomena including unsteady boundary layer separation, receptivity and instability of the shear layer, convection, amplification and saturation of shear layer instabilities, shear layer impingement, and noise radiation. These time-dependent phenomena are linked through a feedback loop, and as a result, the fluctuations in the cavity are strong, and resonance of the cavity flow occurs at distinct modes or tones. 
In a recent computational study, the authors demonstrated the suppression of resonance in a supersonic cavity flow using jet blowing. Time-accurate, two-dimensional, Reynolds-Averaged Navier-Stokes simulations of the cavity flow were employed. A small jet, placed at the front lip of the cavity, was found to be effective in reducing the amplitude of the pressure fluctuations in the cavity. The effectiveness of the control was found to strongly depend upon the amplitude and frequency of the blowing jet. Spatial correlations of unsteady pressures sampled in the cavity showed that the timing of the events were unaffected by the blowing. Auto-correlation analysis however found that size of the large-scale structures in the cavity shear layer were significantly smaller with jet blowing; this observation is consistent with the reduction in the intensity of the cavity oscillations. The potential of the small jet to form the basis of an adaptive control scheme motivated the present wind tunnel experiments using oscillatory blowing.

The concept of oscillatory blowing is an effective method to delay flow separation, and thus enhance lift, on airfoils. ${ }^{11-13}$ The oscillatory blowing, with zero or non-zero net mass flux, has been shown to be more effective than steady blowing. The experiments indicate that the oscillatory blowing periodically transports high momentum, large-scale, "packets" of fluid towards the airfoil surface. Thus the oncoming boundary layer is better able to withstand the higher-pressure gradients. For the present application, steady and oscillatory blowing were applied ahead of the cavity front wall. The intent is to use the forcing as a means to interrupt the sequence of events in the feedback loop. 


\subsection{Experimental Methods}

\subsection{Wind Tunnel}

The experiment was conducted in the Probe Calibration Tunnel (PCT) at the NASA Langley Research Center. PCT is a blow-down tunnel with a capability for the independent control of Mach number, Reynolds number, and total temperature. A highpressure bottle field and steam heater system is used to provide dried, pressurized air to the PCT. The tunnel stagnation temperature can be varied from $255 K$ to $367 K( \pm 0.5 K)$, and the tunnel stagnation pressure from $0.2 \mathrm{~atm}$. to $10 \mathrm{~atm}\left( \pm 1.4 \times 10^{-4}\right.$ atm $)$. Antiturbulence screens and a sintered plate located in the settling chamber are used to condition the flow. The nozzle contracts from a circular inlet of $30.5 \mathrm{~cm}$ (12in) diameter to a $5.1 \mathrm{~cm}(2 \mathrm{in}) \times 15.2 \mathrm{~cm}(6 \mathrm{in})$ rectangular nozzle exit. The test section is located, downstream of the nozzle exit, within a plenum, and is equipped with rectangular Schlieren windows for optical access. The flow exits through a diffuser and is dumped to atmosphere. Prior to the cavity flow experiment, a pitot rake was used to measure the flow exiting the nozzle; for this survey, the cavity model was absent. The flow survey at a Mach number of 0.72 is shown in Figure 1. The boundary layer thickness is $0.6 \mathrm{~cm}$ $(0.22 \mathrm{in})$, and the boundary layer is seen to be quite two-dimensional across the span.

\subsection{Cavity Model}

The cavity model is mounted $30 \mathrm{~cm}(11 \mathrm{in})$ downstream of the nozzle exit. The cavity has dimensions of $15.2 \mathrm{~cm}(6 \mathrm{in})$ in length, $3.8 \mathrm{~cm}(1.5 \mathrm{in})$ in depth, and $5.1 \mathrm{~cm}(2 \mathrm{in})$ in width respectively; the cavity length-to-depth ratio of four is representative of those encountered in landing gear wheel bays. The cavity is instrumented with dynamic 
pressure transducers and static pressure taps for measurement of fluctuating and timemean pressures respectively. Two dynamic pressure transducers are flush mounted along the centerline of the cavity walls: one transducer at the base of the front wall and the second on the rear wall, $2.3 \mathrm{~cm}(0.9 \mathrm{in})$ below the cavity lip. The pressure data were sampled at $10,240 \mathrm{kHz}$ and low-pass filtered at $4 \mathrm{kHz}$.

\subsection{Actuator}

The actuator is positioned upstream of the cavity front wall as shown in Figure 2. The actuator, Figure 3, is designed to operate in one of three modes: steady blowing, oscillatory blowing with a non-zero net mass flux, or oscillatory blowing with a zero net mass flux. Filtered, pressurized air, controlled through a flow control valve is supplied to the hollow rotor of a rotor-stator pair. The motor-driven rotor has slots placed equally around its perimeter. When a slot on the rotor is aligned with the single slot on the stator, air enters the delivery chamber. The maximum flow rate is $300 S L P M$. For steady blowing, the rotor is locked in an "open" position. For oscillatory blowing, the actuator is designed to generate a pulse train of up to $750 \mathrm{~Hz}$. For oscillatory blowing, flow is removed by vacuum from the delivery chamber; a second flow control valve is used to control this flow. Removing a mean flow unequal, or equal, to that entering the rotor generates a non-zero, or zero net mass flux, oscillatory blowing. Within the delivery chamber the adiabatic wall temperature and the unsteady wall pressure are measured. The air exiting from the chamber is introduced into the cavity flow through a slot or pair of holes located $0.25 \mathrm{~cm}(0.1 \mathrm{in})$ upstream of the leading edge of the cavity. In the experiment, seven interchangeable plates, that gave a range of hole sizes, shapes, and blowing directions, were examined. The details of the hole geometries are summarized in 
Table 1. Each hole plate has two holes that are spaced $1.52 \mathrm{~cm}(0.6 \mathrm{in})$ apart, and are equidistant from the tunnel sidewalls with the exception of Plate 6 which contained a spanwise slot. The holes have a pitch angle of $90^{\circ}$ with respect to the free stream direction and a skew angle, with respect to the direction of the span of the cavity that is listed in Table 1. The following results will be given for plate 5 only unless stated otherwise. The velocities of the jet exiting the holes were estimated in a bench-top experiment.

Table 1. Summary of hole plate characteristics.

\begin{tabular}{cccc}
\hline Plate \# & Width / diameter & Length & $\begin{array}{c}\text { Blowing angle } \\
(\text { skew })\end{array}$ \\
\hline 1 & $0.16 \mathrm{~cm}(0.063 \mathrm{in})$ & & $90^{\circ}$ \\
2 & $0.16 \mathrm{~cm}(0.063 \mathrm{in})$ & $45^{\circ}$ \\
3 & $0.289 \mathrm{~cm}(0.113 \mathrm{in})$ & & $90^{\circ}$ \\
4 & $0.16 \mathrm{~cm}(0.063 \mathrm{in})$ & $0.41 \mathrm{~cm}(0.16 \mathrm{in})$ & $90^{\circ}$ \\
5 & $0.16 \mathrm{~cm}(0.063 \mathrm{in})$ & $0.41 \mathrm{~cm}(0.16 \mathrm{in})$ & $45^{\circ}$ \\
6 & $3.81 \mathrm{~cm}(1.5 \mathrm{in})$ & $0.16 \mathrm{~cm}(0.063 \mathrm{in})$ & $90^{\circ}$ \\
7 & $0.32 \mathrm{~cm}(0.125 \mathrm{in})$ & & $90^{\circ}$ \\
\hline
\end{tabular}

\subsection{Actuator Calibration}

A bench-top experiment was conducted to characterize the performance of the actuator. This characterization was necessary as the jet velocities, and thus the mean and fluctuating momentum coefficients, could not be measured during the wind tunnel tests. In the bench-top experiment, the jet velocities were measured while the actuator was operated over a range of frequency and mass flow rates; the momentum coefficients were 
then estimated from these measurements. The velocities were measured using a hot-wire, of diameter $5.0 \times 10^{-3} \mathrm{~mm}(0.0002 \mathrm{in})$, operated with a constant temperature anemometer; the conditions in the actuator's delivery chamber were simultaneously measured. The hot-wire and unsteady pressure data were sampled at $10 \mathrm{kHz}$ and low-pass filtered at $4 k H z$. Since the hot-wire cannot sense flow direction, the hot-wire data were de-rectified using the pressure signal as a reference. The de-rectified and rectified hot-wire data are compared with the pressure data in Figure 4a. The corresponding spectra of the hot-wire and pressure data are compared in Figure $4 \mathrm{~b}$. The dominant peak at $140 \mathrm{~Hz}$ corresponds to the forcing frequency; the harmonics of this frequency are also observed and are present due to the on-off action of the rotor-stator design in the actuator. The relative amplitudes of the fundamental-to-harmonics are similar for the de-rectified hot-wire and pressure data. The dimensionless mean and fluctuating momentum coefficients, $c_{\mu}$ and $\left\langle c_{\mu}\right\rangle$, respectively, were used to quantify the performance of the blowing. The coefficients are given as:

$$
\begin{gathered}
c_{\mu}=\frac{\rho u^{2} A_{j}}{q A_{r}} \\
<c_{\mu}>=\frac{\rho u^{\prime 2} A_{j}}{q A_{r}}
\end{gathered}
$$

The measured jet velocity, for steady blowing mode of operation, agreed well with the jet exit velocity determined from the isentropic relations and the ratio of the delivery chamber pressure to the ambient pressure. For oscillatory blowing, the approach 
developed by Seifert and Pack ${ }^{13}$ was followed to estimate $\left\langle\mathrm{c}_{\mu}\right\rangle$. Specifically, the relationship:

$$
u^{\prime 2} \propto \frac{p^{\prime}}{\rho}
$$

is used to correlate $u^{\prime}, p^{\prime}$, and $\rho$ measured in the bench-top tests with the $p^{\prime} / \rho$ measured in the wind tunnel experiments; $\left\langle c_{\mu}\right\rangle$ could then be estimated. The fluctuating velocity is plotted against the fluctuating pressure measured in the delivery chamber, Figure 5, for the zero net mass flux, oscillatory blowing mode of operation in a bench-top test. These data span a range of forcing frequencies and mean mass flow rates. The mass flow rates are shown in the legend. Figure 6 shows the linear curve fits to the calibration data for forcing frequencies of $150 \mathrm{~Hz}$ and $400 \mathrm{~Hz}$. Similar curve fits were obtained for all the forcing frequencies examined in the bench-top tests. The jet momentum versus forcing frequency is plotted for several levels of mean flow rates is shown in Figure 7. The jet momentum varies with both forcing frequency and mean flow. For a given mean flow, the jet momentum shows a maximum around $140 \mathrm{~Hz}$. This is a characteristic frequency of the actuator's delivery chamber, and the maximum is more pronounced at the higher mean flow rates.

\subsection{Results}

The cavity tests were conducted at a Mach number of 0.15 and a unit Reynolds number of $5.9 \times 10^{6} / \mathrm{m}$. A tunnel total pressure of $186.2 \mathrm{kPa}(27 \mathrm{psi})$ was used in order that the ambient room pressure acted as the vacuum for the zero net mass flux, oscillatory blowing. 


\subsection{Steady Blowing}

The time traces of the pressure fluctuations at the cavity rear wall location, with and without steady blowing, are compared in Figure 8. Without blowing the amplitudes are relatively large, and spike-like events are quite pronounced. In contrast with steady blowing, $\mathrm{c}_{\mu}=0.015$, the amplitudes are smaller and the oscillations are more regular. The spectra of the fluctuating pressures in the cavity are presented in Figure 9. Three levels of steady blowing, $c_{\mu}=0.003,0.009$ and 0.015 , are compared with the no blowing (baseline) case for the front, Figure $9 \mathrm{a}$, and rear wall, Figure $9 \mathrm{~b}$, locations. The experimentally measured resonant frequencies are compared in Table 2 with the theoretical frequencies determined from Rossiter's ${ }^{14}$ semi-empirical equation. From the baseline spectra, the second mode is seen to be the most dominant resonant mode, and has amplitudes of $112 \mathrm{~dB}$ and $131 \mathrm{~dB}$ at the front and rear wall locations, respectively. The spectra at the rear wall also show resonant peaks at $100 \mathrm{~Hz}$, that is a characteristic of the actuator. With steady blowing the amplitudes of all the cavity modes decreases. The respective decreases in the amplitude of the dominant second mode are measured as 6,8 and $8 d B$ at the front location, and 5,9 and $11 \mathrm{~dB}$ at the rear wall location.

Table 2. Calculation of resonant frequencies.

\begin{tabular}{ccc}
\hline Mode & $\begin{array}{c}f(\mathrm{~Hz}) \\
\text { (experiment) }\end{array}$ & $\begin{array}{c}f(\mathrm{~Hz}) \\
\text { (theory) }\end{array}$ \\
\hline 1st & 210 & 153 \\
2nd & 370 & 358 \\
3rd & 540 & 562 \\
4th & 750 & 767 \\
\hline
\end{tabular}


The model for cavity resonance consists of a series of time-varying events in a feedback loop. Cross-correlations, obtained using the two cavity fluctuating pressures, analyzed together with the above spectra provide details of the modifications to the feedback loop due to blowing. The coherence and cross-spectrum phase between the two pressure signals are presented in Figure 10. The coherence function, Figure 10a, has highlevels at the resonant peaks indicating that the two signals are phase correlated. The level of the coherence function is nearly 1 at the dominant second mode, for both the baseline and the $c_{\mu}=0.003$ blowing case indicating that the signals are highly phase correlated. At the higher level of blowing, $c_{\mu}=0.015$, the level is substantially reduced indicating a smaller degree of phase correlation. The level of coherence is low in the range of the actuator's characteristic frequency indicating that there is no phase correlation between the actuator's characteristic resonance and the resonance of the cavity. The phase of the cross-spectrum, Figure 10b, shows a phase shift of about $0 \mathrm{rad}$ at the cavity resonant frequencies. The phase shift is little changed with blowing indicating that the wave structure is unaltered. The time delay between the two measured signals is shown in the cross-correlation function presented in Figure 11. The measured time delays are invariant with blowing suggesting that the time-varying events in the cavity feedback loop are unaffected by steady blowing.

\subsection{Oscillatory Blowing}

Zero net mass flux, oscillatory blowing was examined over a range of momentum coefficients and forcing frequencies. The measured fluctuating pressure in the delivery chamber of the actuator is plotted against the forcing frequency for all the input/output 
mass flow rates examined here, Figure 12. The fluctuating momentum coefficients determined using the calibration of the actuator in the bench-top experiment are presented in Figure 13. For the present work the maximum of the range of the fluctuating momentum coefficients, $\left\langle c_{\mu}\right\rangle=0.0016$, is approximately half the lowest mean momentum coefficient, $c_{\mu}=0.003$, which was examined for the steady blowing above.

The time trace of pressure fluctuations at the rear wall, with a low-level of oscillatory blowing, $\left\langle c_{\mu}>=0.0002, f_{f}=460 \mathrm{~Hz}\right.$, is shown in Figure 14. The spectra at the front and rear wall locations are shown in Figure 15 for forcing frequencies of $f_{f}=120,280$ and $460 \mathrm{~Hz}$. The respective changes in the amplitude of the dominant second mode are $+4,-4$, and $-8 d B$ at the front locations and $+4,-3$, and $-7 d B$ at the rear wall locations. The forcing at $f_{f}=120 \mathrm{~Hz}$ amplifies the dominant second mode as the third harmonic of the forcing, $360 \mathrm{~Hz}$, is close to the resonant frequency, Table 2 . This observation re-emphasizes a result in the previous computations of the authors ${ }^{8}$; that is forcing at a resonant frequency, or its higher harmonics, is deleterious. For the other forcing frequencies, $f_{f}$ $=280 \mathrm{~Hz}$ and $460 \mathrm{~Hz}$, the frequency of forcing is evident in the spectra.

The spectra at fluctuating jet momentum coefficients of $\left\langle c_{\mu}\right\rangle=0.0008$ and 0.0013 are presented in Figures 16 and 17, respectively. The measurement again show that harmonic forcing, $f_{f}=120 \mathrm{~Hz}$, reinforces the cavity resonance; whereas forcing at $f_{f}=280 \mathrm{~Hz}$ and $460 \mathrm{~Hz}$, is effective in controlling the cavity resonance. (Note, that no data are presented for $\left\langle\mathrm{c}_{\mu}\right\rangle=0.0013, f_{f}=460 \mathrm{~Hz}$.) The reductions in the amplitude of the dominant second mode at $\left\langle\mathrm{c}_{\mu}\right\rangle=0.0008$ are 8 and $9 \mathrm{~dB}$ at the front location, and 9 and $10 \mathrm{~dB}$ at the rear wall location for $f_{f}=280 \mathrm{~Hz}$ and $460 \mathrm{~Hz}$ respectively. These amplitude reductions are comparable to the effect of steady blowing, yet are accomplished with an order of 
magnitude smaller jet momentum coefficient. Figure 18 compares the level of unsteady blowing needed to obtain similar amplitude reductions for the second cavity mode. Forcing at $460 \mathrm{~Hz}$ was more efficient in reducing the amplitude of the second mode by an order of magnitude smaller than forcing at $280 \mathrm{~Hz}$.

The coherence and cross-spectrum phase for oscillatory blowing at $\left\langle\mathrm{c}_{\mu}\right\rangle=0.0002$ are compared in Figure 19b. In comparison with the baseline case, the level of the coherence function, Figure 19a, is high at the forcing frequencies as may be expected. The dominant second mode has a level of nearly 1 for the forcing frequencies $f_{f}=120$ and $280 \mathrm{~Hz}$; at the highest forcing frequency, $f_{f}=460 \mathrm{~Hz}$, the level is lower, perhaps due the near suppression of the resonant mode at the front location. The phase of the cross-spectrum, Figure 19b, shows that the wave structure is unaltered.

The cross-correlation function presented in Figure 20 shows the effect of oscillatory blowing, $\left\langle\mathrm{c}_{\mu}\right\rangle=0.0002$, on the time delays. In contrast to the steady blowing, the oscillatory blowing has a dramatic effect on the timing of events in the feedback loop of the cavity flow. At $f_{f}=120 \mathrm{~Hz}$ the time delays are unchanged; at $f_{f}=280 \mathrm{~Hz}$ the time delays are increased; and at $f_{f}=460 \mathrm{~Hz}$ the delays are decreased. These results indicate that forcing at a harmonic frequency of the cavity resonance, reinforces its' natural tendency to resonate. On the other hand, forcing at other frequencies interrupts the resonance of the cavity.

\subsection{Hole Plate Performance Summary}

Figures 21 through 24 show the effect of $\left\langle\mathrm{c}_{\mu}\right\rangle$ on the SPL for all plates. The plots show the SPL reduction at the rear wall location; the reduction was determined by the difference between the SPL cases with and without blowing. A positive $\Delta \mathrm{dB}$ indicates an 
increase in SPL while a negative $\triangle \mathrm{dB}$ indicates a decrease in SPL compared to the baseline case. The accuracy in the $\Delta \mathrm{dB}$ measurements is $\pm 1 \mathrm{~dB}$. For all figures, the forcing frequency is $460 \mathrm{~Hz}$. Figure 21 shows the amplitude reduction for the first cavity mode $(150 \mathrm{~Hz})$; Figure 22 shows the amplitude reduction for the second cavity mode $(370 \mathrm{~Hz})$; and Figure 23 shows the amplitude reduction at the third cavity mode $(540 \mathrm{~Hz})$. Figure 24 shows the amplitude reduction at the forcing frequency, $460 \mathrm{~Hz}$. At the first cavity mode, Figure 21 , the amplitude increases proportionally with the blowing level for all plates. The rate of increase for all plates is the same except for the slot, plate 6, which has a smaller rate of increase. The overall amplitude increase is relatively small. At the dominant second mode, Figure 22, the amplitudes decrease proportionally with the blowing level for all plates except plate 6 , the slot. The rate of decrease is the same for all plates, except the slot, which remains constant. The larger hole size plates are more efficient in reducing the amplitudes. The level of $\Delta \mathrm{dB}$ reduction is significant. At the third cavity mode, Figure 23, the amplitude decreases proportionally with the blowing level for all plates except for the slot, for which the amplitude remains constant. The rate of decrease is the same for all plates with the exception of the slot. The level of decrease is relatively insignificant. At the forcing frequency, Figure 24 , the amplitudes increase proportionally with the blowing level for all plates with the exception of plate 6 , the slot, which remains relatively constant. The plate with the smallest sized holes had the least deleterious effect at the lower blowing rates. The overall amplitude increases are significant. 


\subsection{Conclusions}

The basic mechanisms of the control of cavity resonance using steady and zero net mass flux, oscillatory blowing are experimentally studied. Steady and oscillatory blowing are both found to be effective in controlling the cavity resonance; however, when the appropriate forcing frequency of oscillatory blowing is used, oscillatory blowing is as effective as steady blowing at momentum coefficients an order of magnitude smaller. The results show that for the oscillatory blowing, the forcing can be selected to be most effective in interrupting the feedback loop of the cavity if the forcing is not at a harmonic frequency of the resonant modes of the cavity. A forcing frequency that is a harmonic frequency only serves to reinforce the natural tendency of the cavity to resonate. The larger sized holes are more efficient in reducing the SPL. In the present work no attempt has been made to optimize the forcing; a knowledge of details of the cavity shear layer are required for this purpose. Hot-wire measurements are planned to accomplish this next goal.

\subsection{References}

1. Chokani, N., "Flow-Induced Oscillations in Cavities - A Critical Survey," DGLR/AIAA Paper 92-01-159, May 1992.

2. Fethney, P., and Jelly, A. H., "Airframe Self-Noise Studies on the Lockheed L1011 Tri-Star Aircraft," AIAA Paper 80-1061, June 1980.

3. Cattafesta III, L. N., Garg, S., Choudhari, M. and Li, F., "Active Control of FlowInduced Cavity Resonance," AIAA Paper 97-1804, July 1997. 
+ Ünalmis, O. H., Clemens, N. T., and Dolling, D. S., "Planar Laser Imaging of High Speed Cavity Flow Dynamics," AIAA Paper 98-0776, January 1998.

s. Zhang, X. and Edwards, J. A., "An Investigation of Supersonic Oscillatory Cavity Flows Driven by a Thick Shear Layer," Aeronautical Journal, Vol. 94, Dec. 1990, pp. $355-364$.

6. Baysal, O., Yen, G.-W. and Fouladi, K., "Navier-Stokes Computations of Cavity Aeroacoustics with Suppression Devices," AIAA/DGLR Paper 92-02-161, May 1992.

7. Kim, I. and Chokani, N., "Navier-Stokes Study of a Supersonic Cavity Flowfield with Passive Control," Journal of Aircraft, Vol.29, Mar.-Apr. 1992, pp. 217-223. (See also AIAA Paper 90-3101)

8. Lamp, A. M. and Chokani, N., "Computation of Cavity Flows with Suppression Using Jet Blowing," Journal of Aircraft, Vol.34, July-Aug. 1997, pp. 545-551. (See also AIAA Paper 96-0446)

9. Morgenstern, A. and Chokani, N., "Hypersonic Flow past Open Cavities," AIAA Journal, Vol. 32, Dec. 1994, pp. 2387-2393. (See also AIAA Paper 93-2969)

10. Tam, C.-J., Orkwis, P. D. and Disimile, P. J., "Algebraic Turbulence Model Simulations of Supersonic Open-Cavity Flow Physics," AIAA Journal, Vol. 34, Nov. 1996, pp. 2255-2260.

"Seifert, A., Bachar, T., Koss, D., Shepshelovich, M. and Wygnaski, I., "Oscillatory Blowing: A Tool to Delay Boundary-Layer Separation," AIAA Journal, Vol. 31, Nov. 1993, pp. 2052-2060.

12. Seifert, A., Bachar, T. and Wygnaski, I., "Delay of Airfoil Stall by Periodic Excitation." J. of Aircraft, Vol. 33, July-Aug. 1996, pp. 691-698. 
13. Seifert, A. and Pack, L. G., "Oscillatory Control of Separation at High Reynolds Numbers," AIAA Paper 98-0214, January 1998.

14. Rossiter, J. E., "Wind-Tunnel Experiments on the Flow over Rectangular Cavities at Subsonic and Transonic Speeds," R. \& M. No. 3438, A. R. C., London, October 1964. 


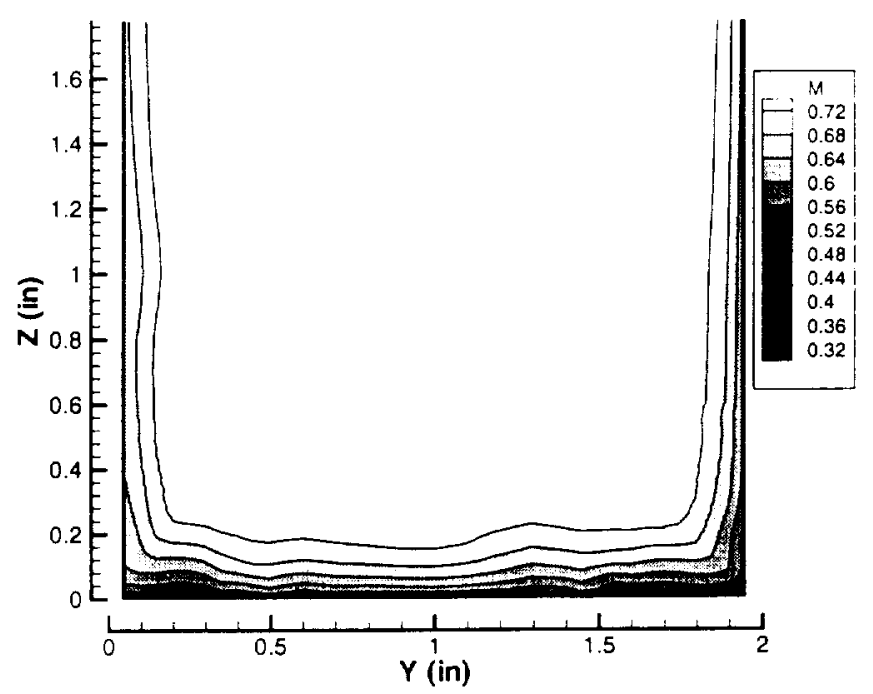

Figure 1: Contours of Mach number at nozzle exit. $M_{\infty}=0.72, \operatorname{Re}=16.4 \times 10^{6} / \mathrm{m}$.

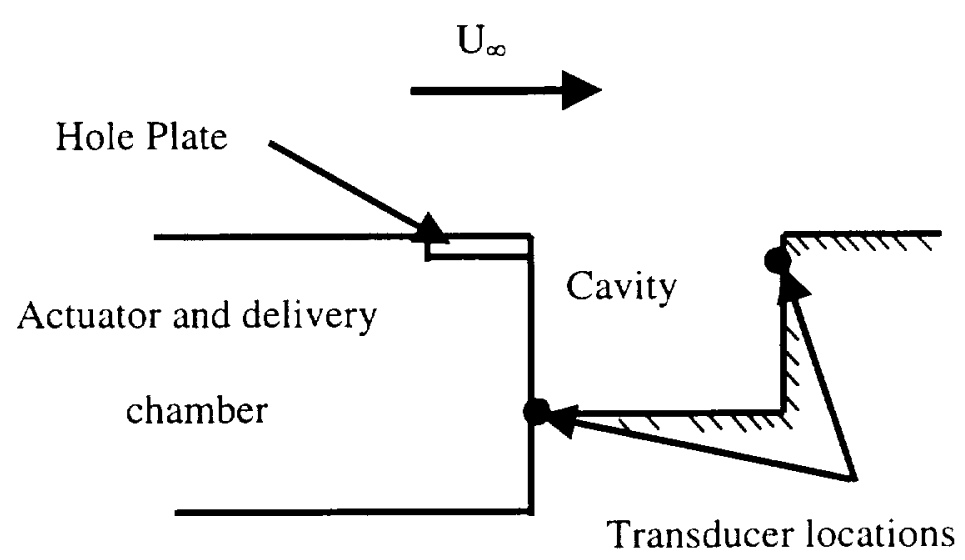

Figure 2: Schematic diagram of actuator and cavity. 


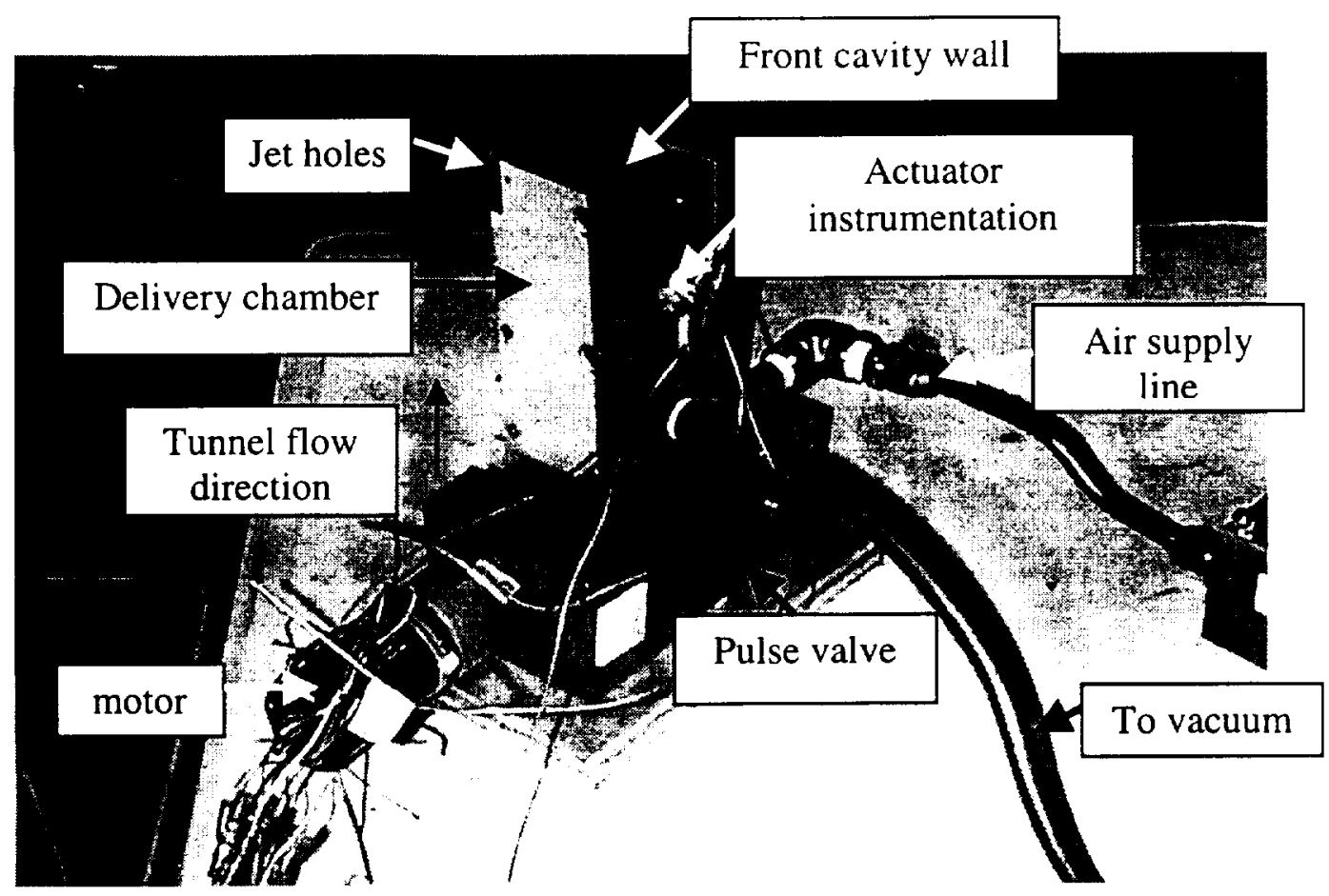

Figure 3: Actuator set-up during bench-top testing.

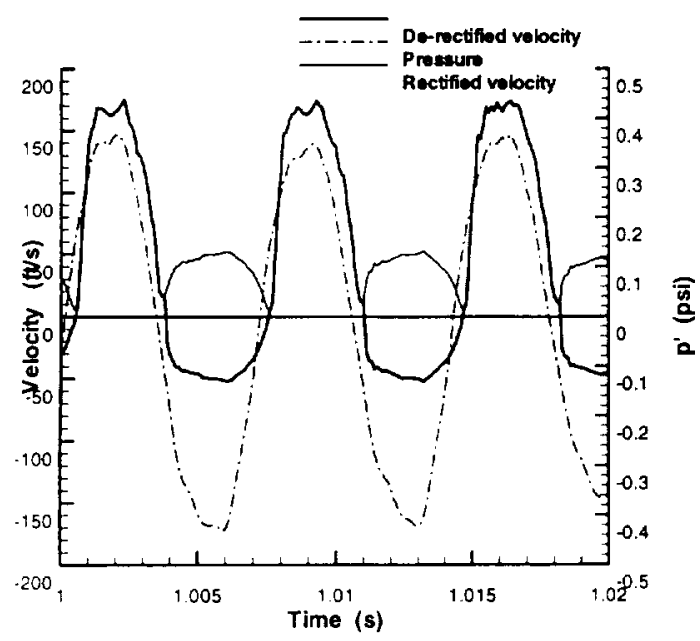

Figure 4a: Time trace of actuator pressure and jet velocity, $\mathrm{f}_{\mathrm{f}}=140 \mathrm{~Hz}$.

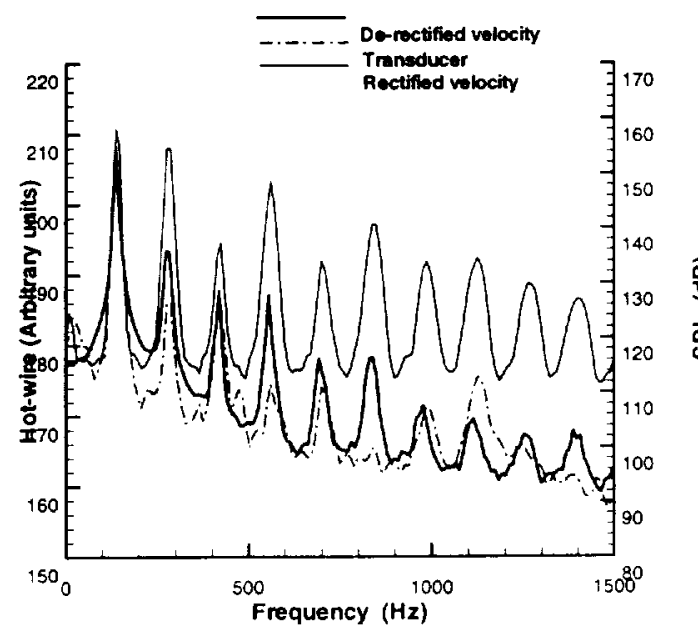

Figure 4b: Spectra of actuator pressure and jet velocity, $\mathrm{f}_{\mathrm{f}}=140 \mathrm{~Hz}$. 


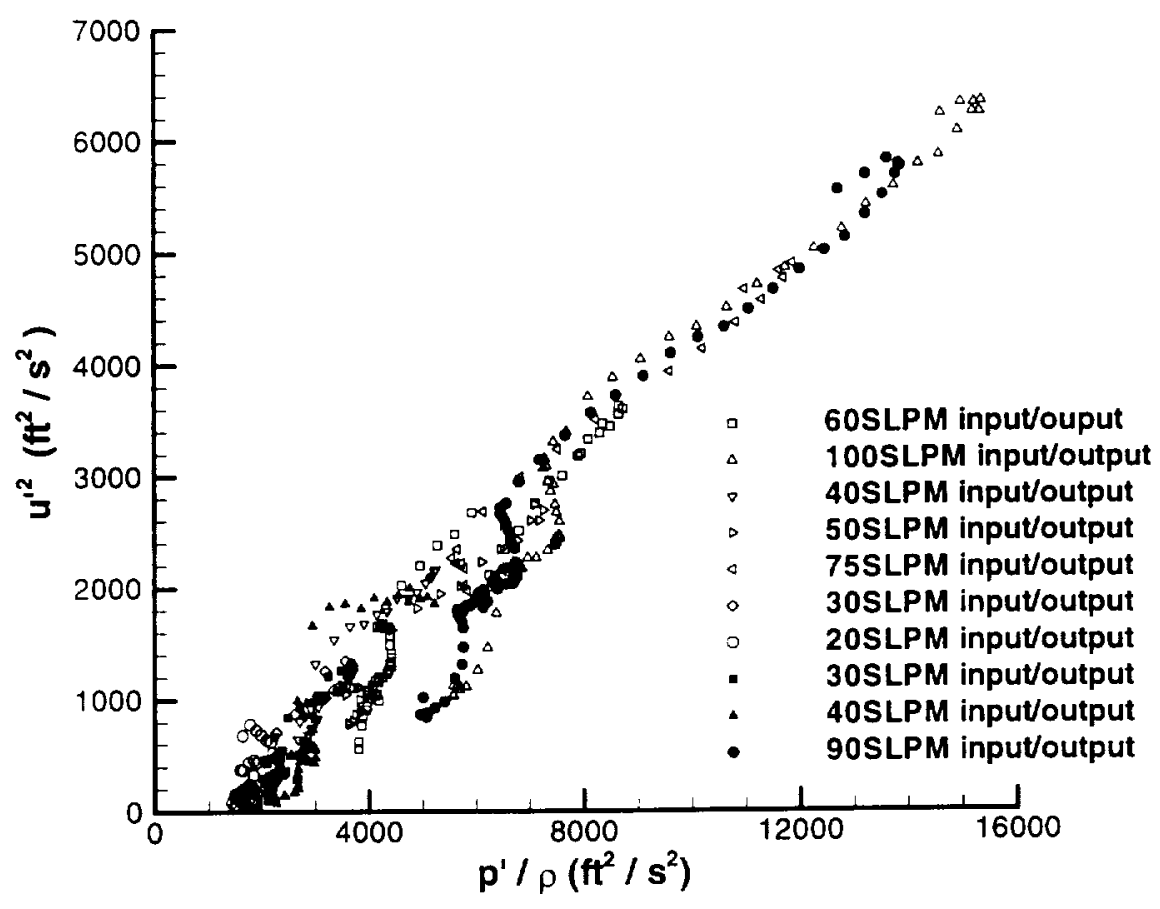

Figure 5: Blowing velocity vs. actuator delivery chamber pressure.

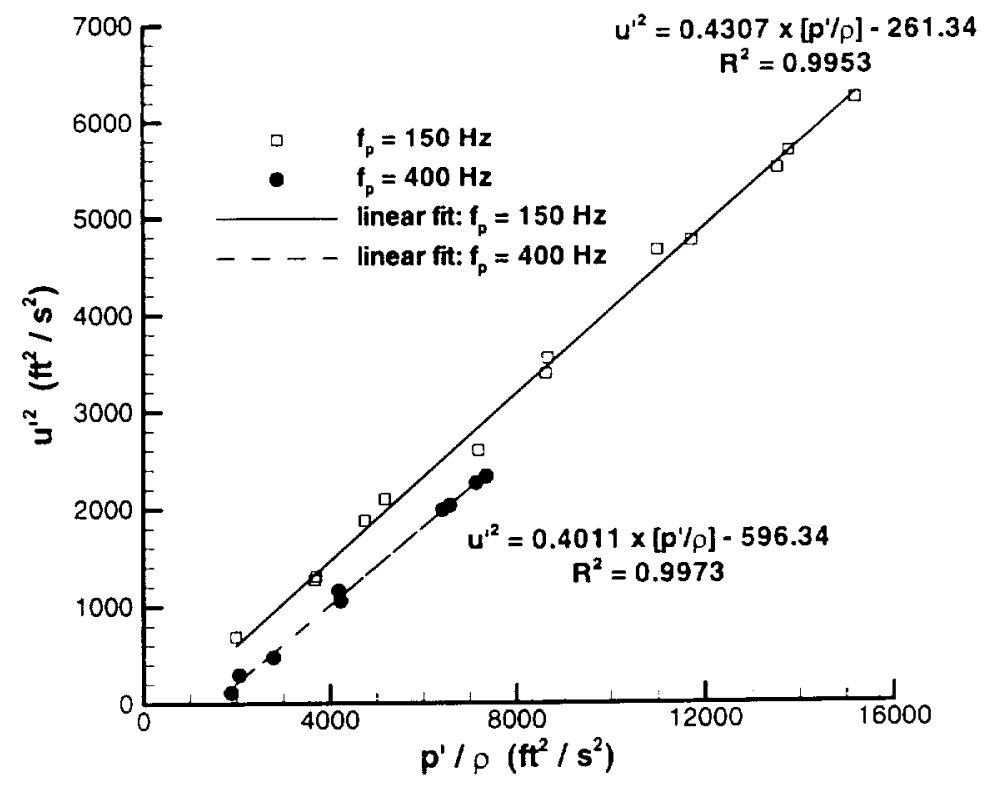

Figure 6: Calibration of blowing velocity vs. actuator delivery chamber pressure. 


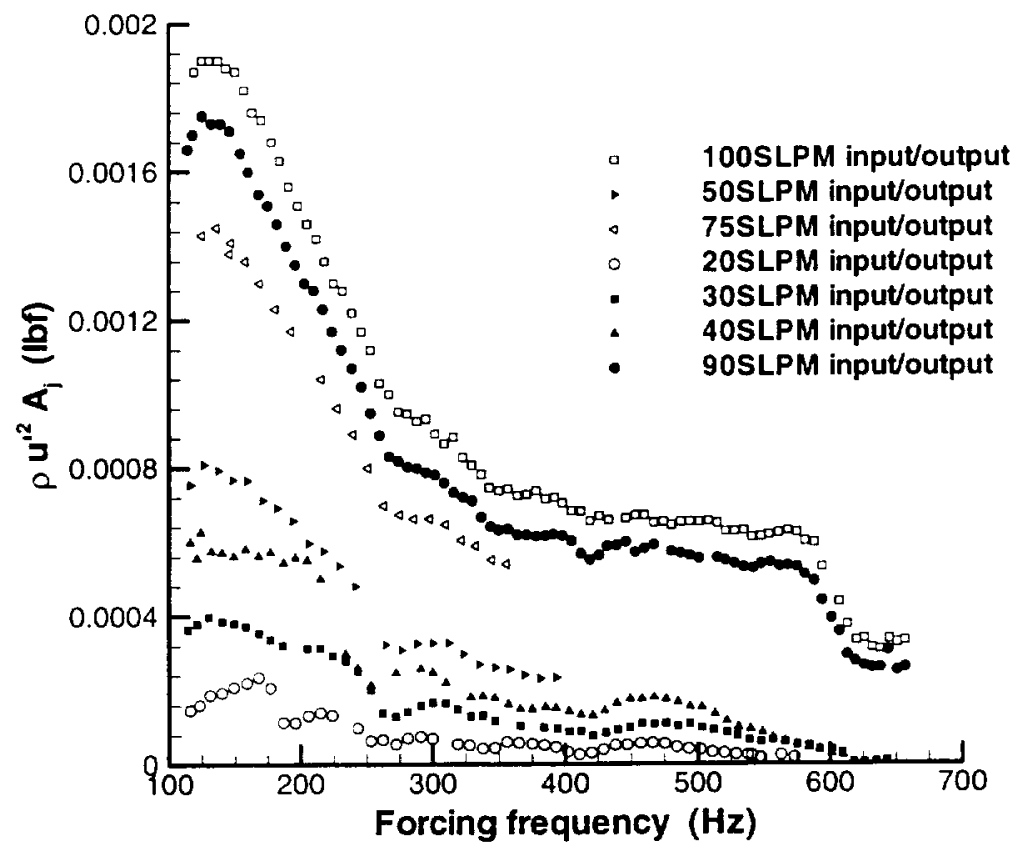

Figure 7: Resonant characteristics of the actuator at different input/output conditions.

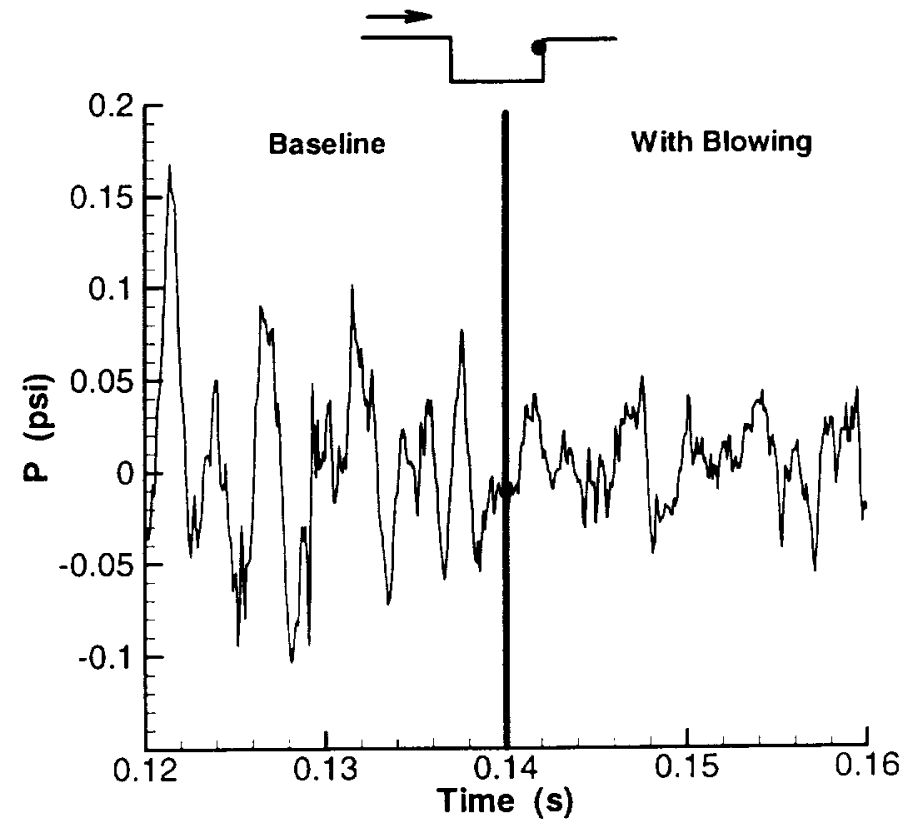

Figure 8: Time traces of pressure fluctuations at rear wall, with and without steady blowing. $c_{\mu}=0.015$. 
(a)

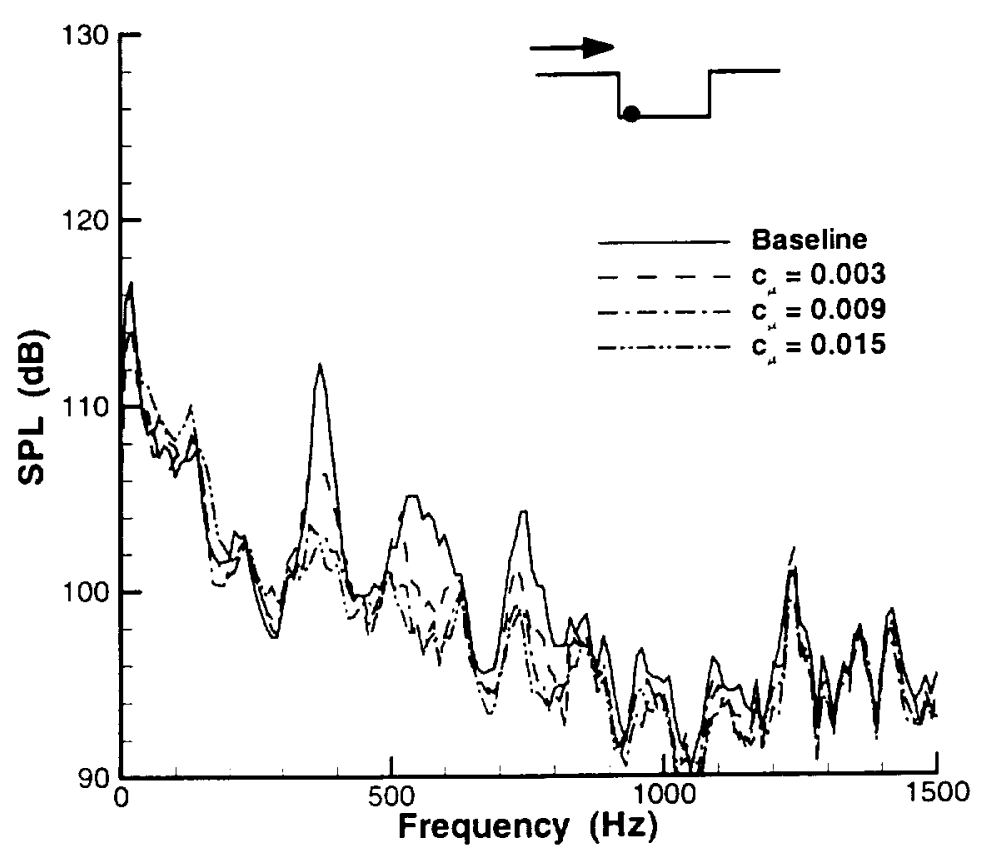

(b)

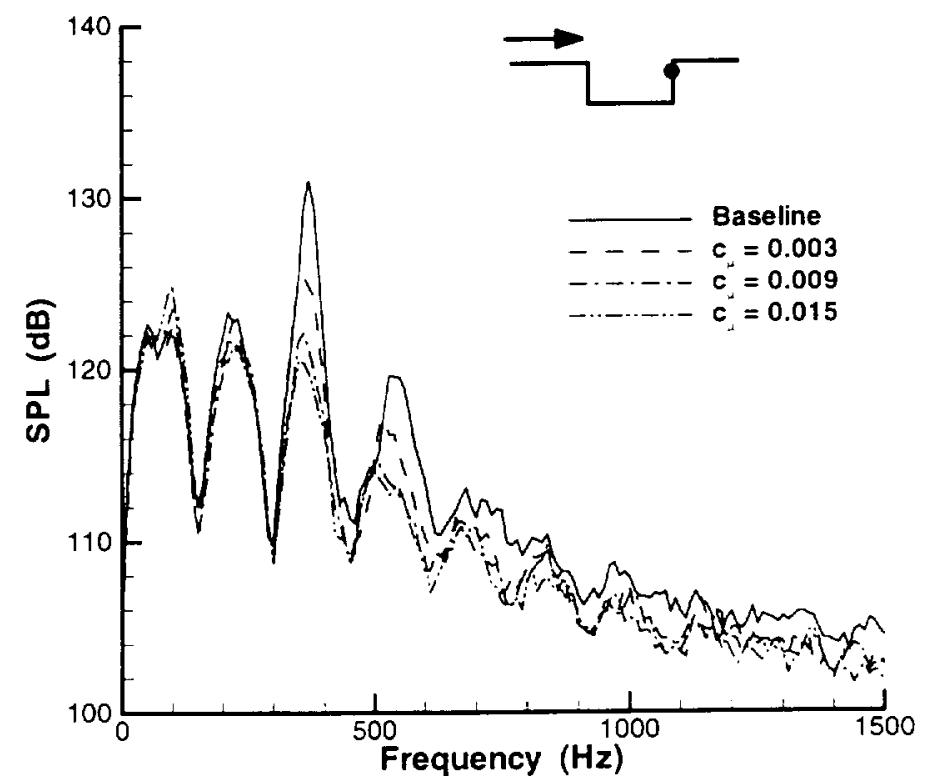

Figure 9: Spectra at the rear wall location: steady blowing.

(a) Floor (b) Rear wall locations. 


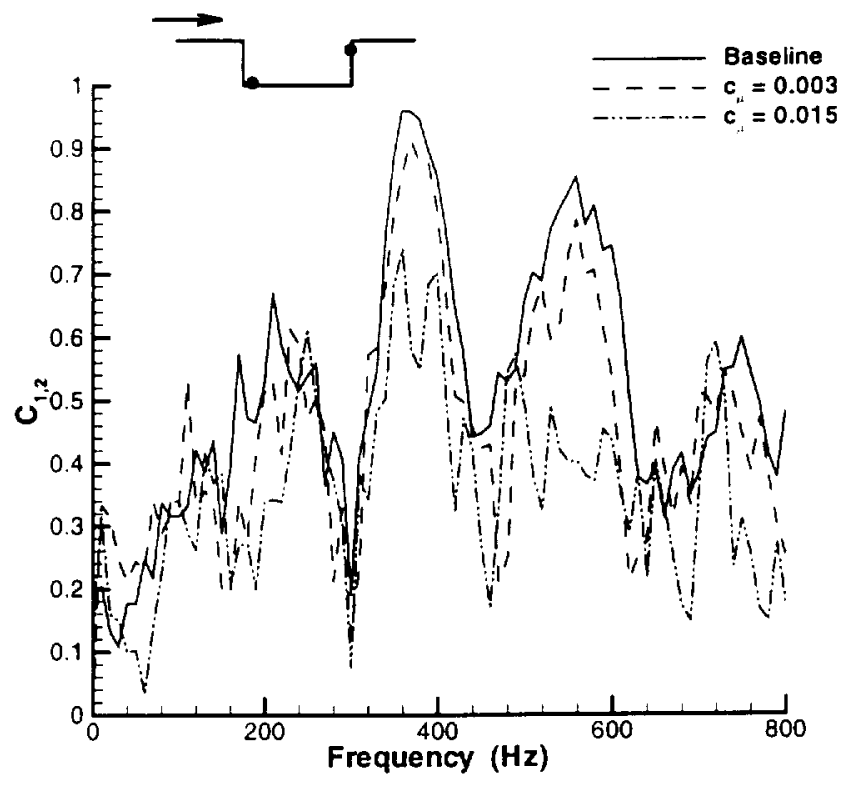

Figure 10a: Coherence between the front and rear wall locations: steady blowing.

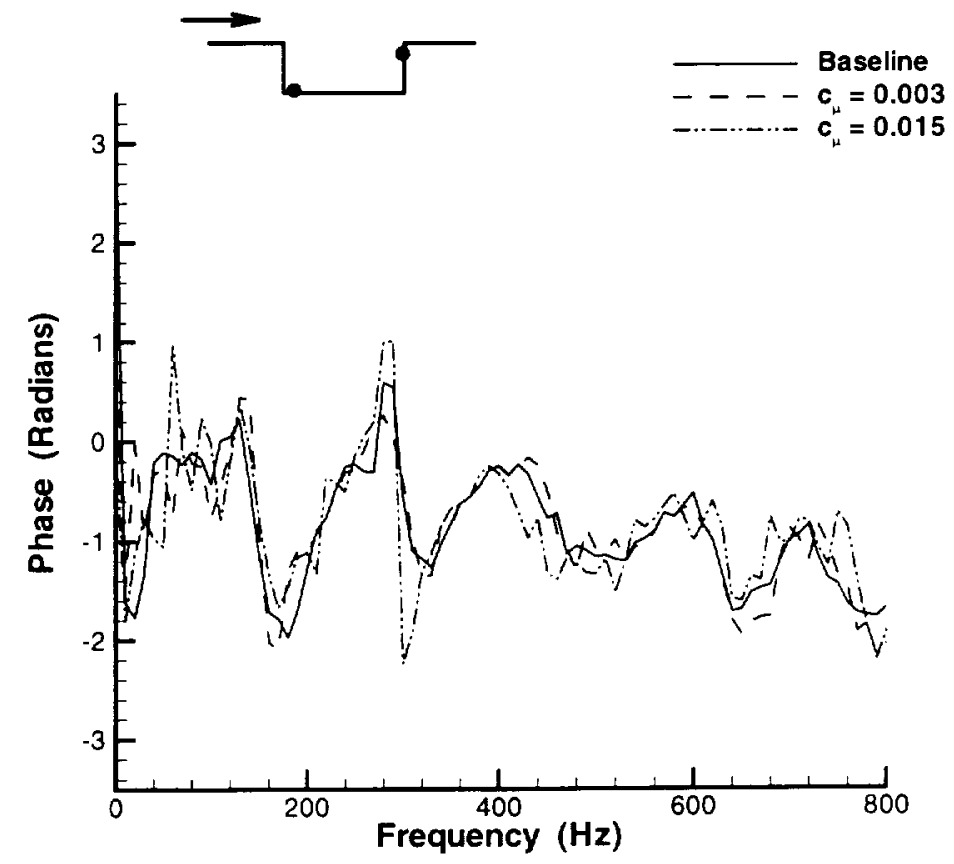

Figure 10b: Phase between the front and rear wall locations: steady blowing 


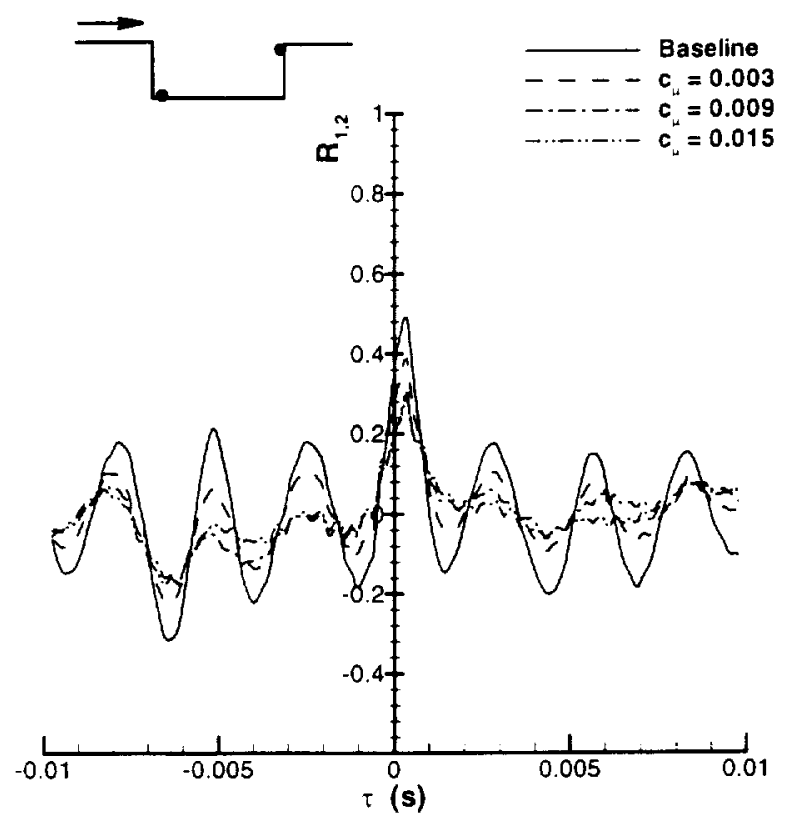

Figure 11: Cross-correlation between the front and rear wall locations: steady blowing.

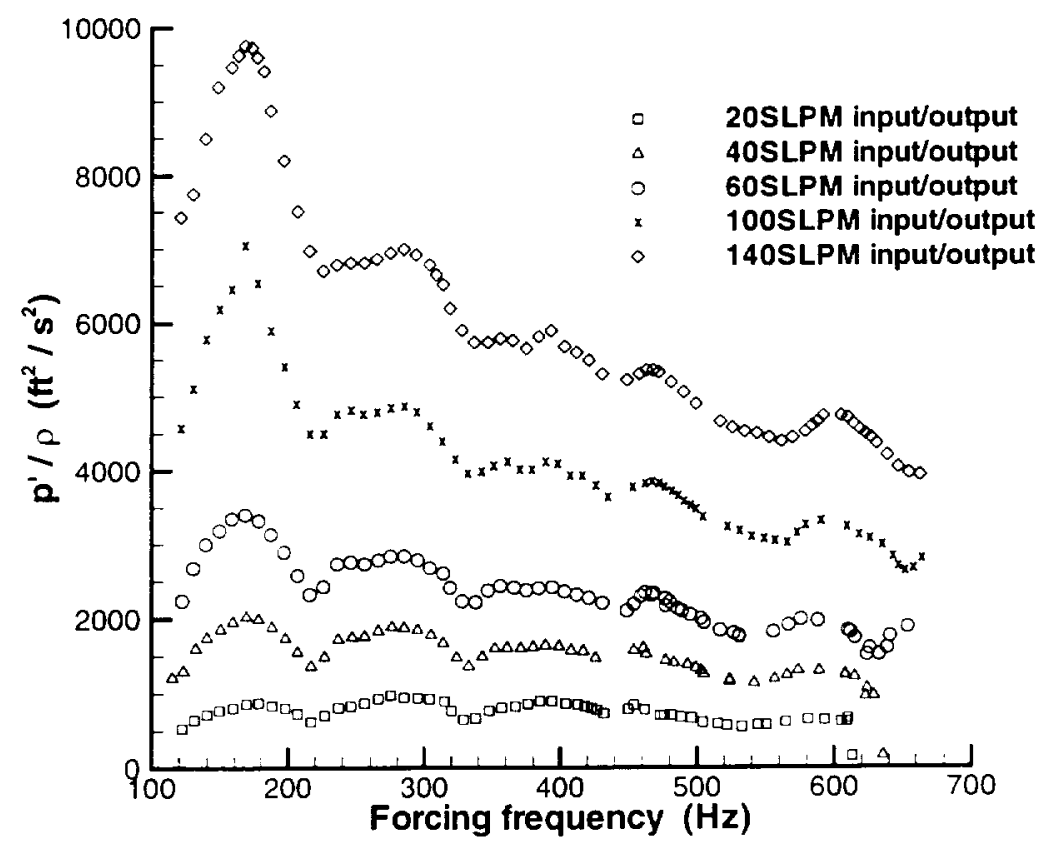

Figure 12: Actuator pressure for oscillatory blowing. 


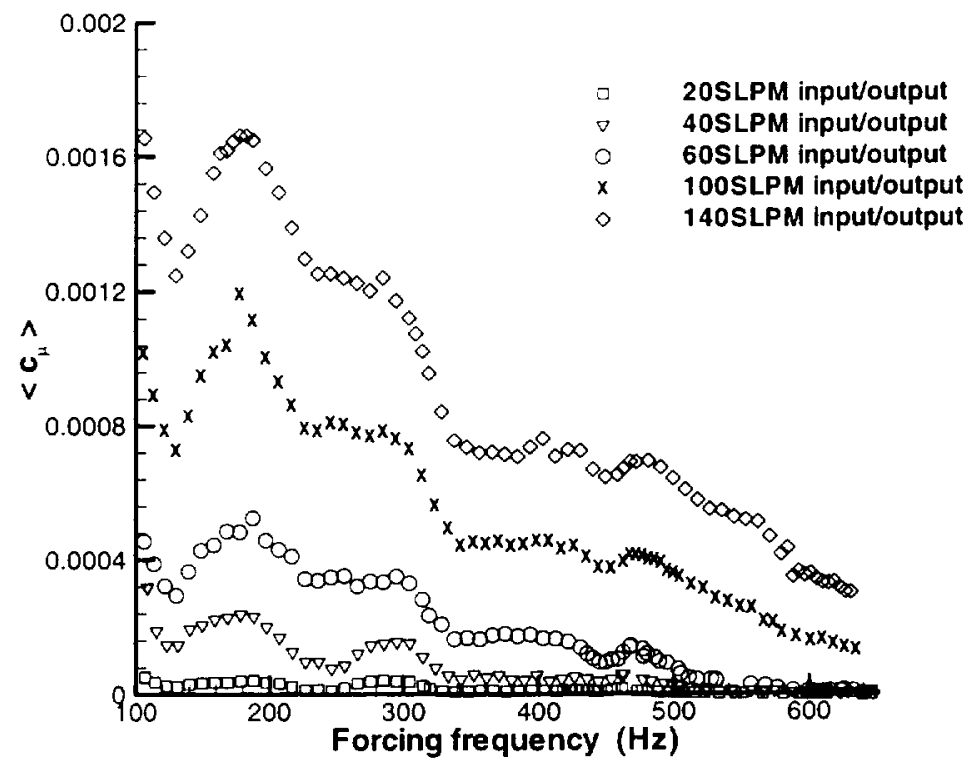

Figure 13: Fluctuating momentum coefficient for oscillatory blowing.

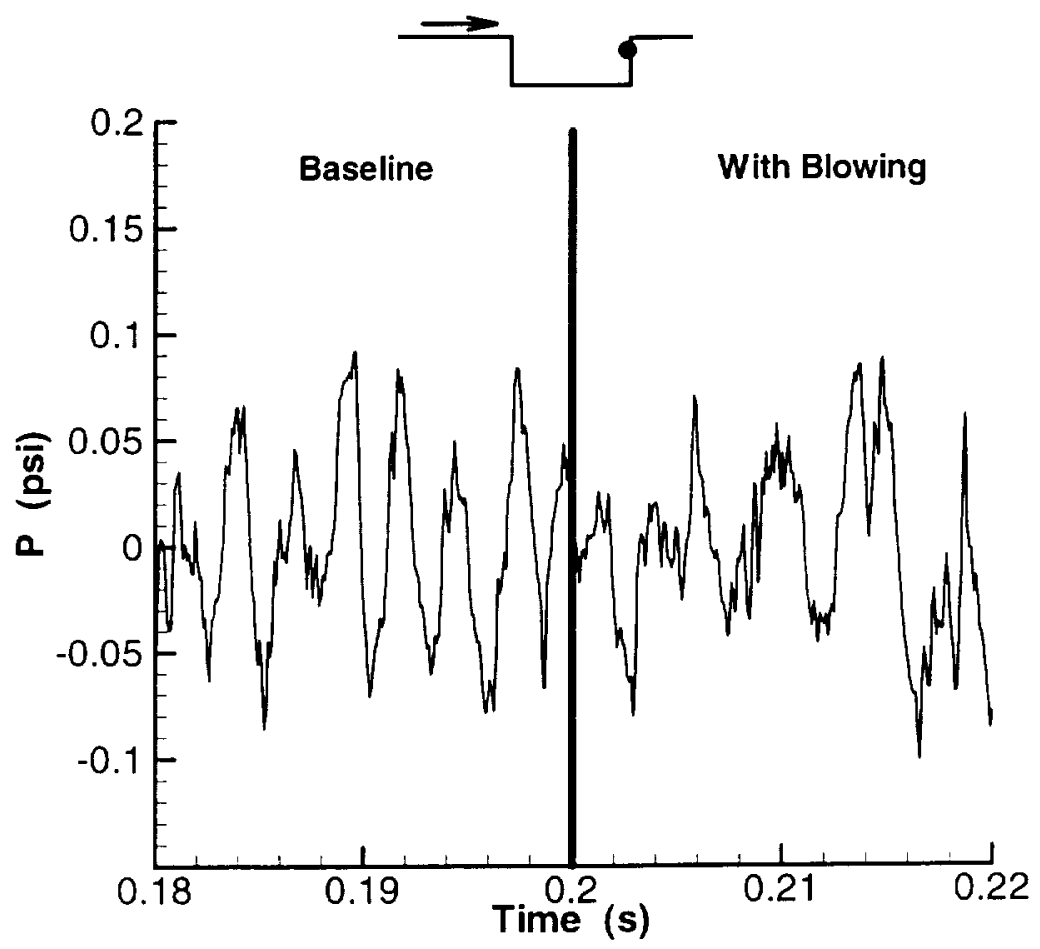

Figure 14: Time traces of pressure fluctuations at rear wall, with $\left(f_{f}=460 H z,\left\langle c_{\mu}>=0.0002\right)\right.$ and without blowing. 
(a)

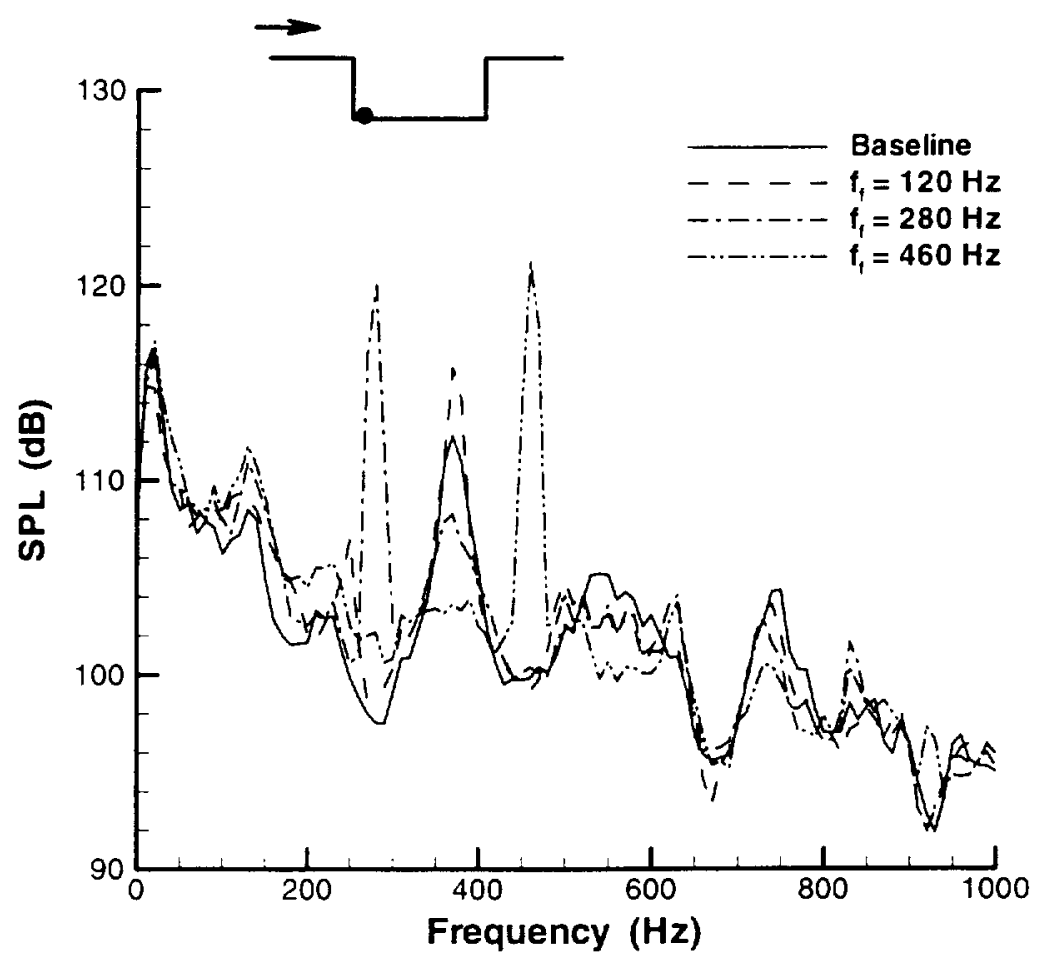

(b)

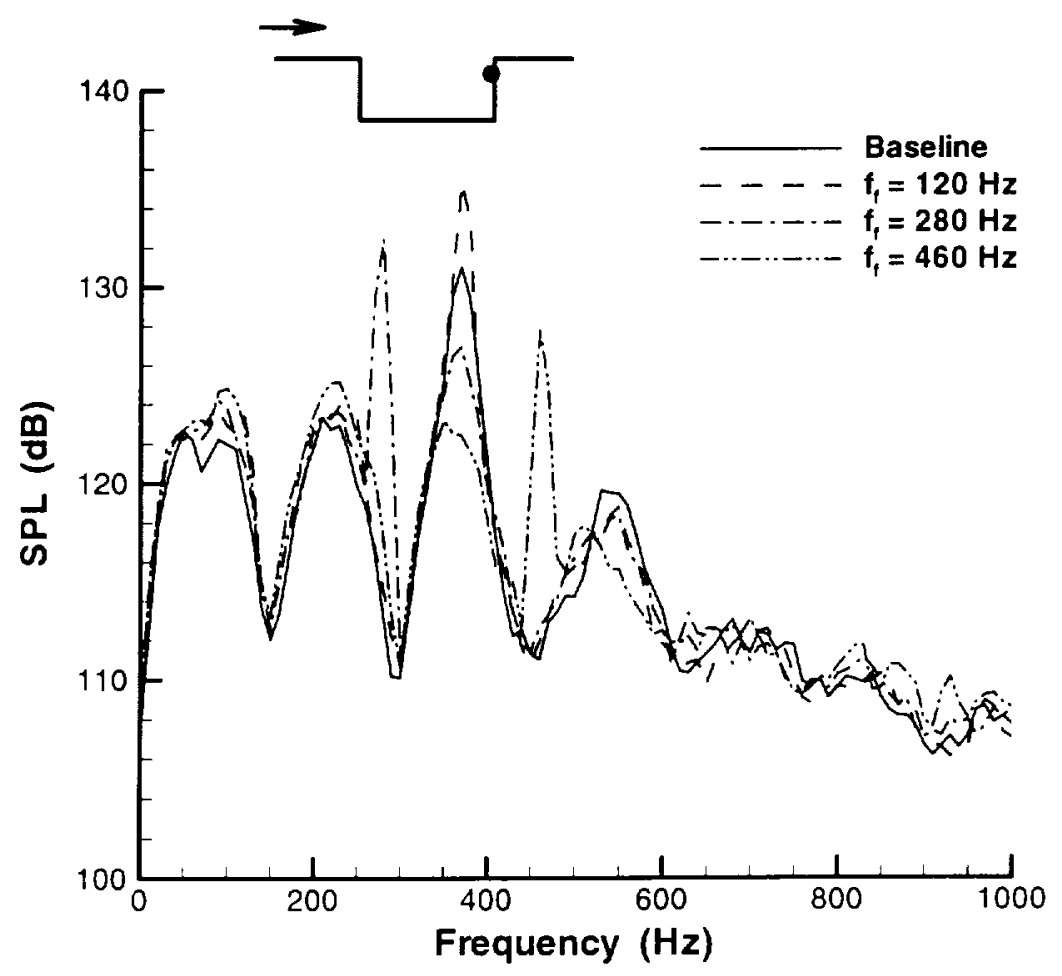

Figure 15: Spectra for oscillatory blowing, $\left\langle c_{\mu}>=0.0002\right.$.

(a) Floor (b) Rear wall locations. 
(a)

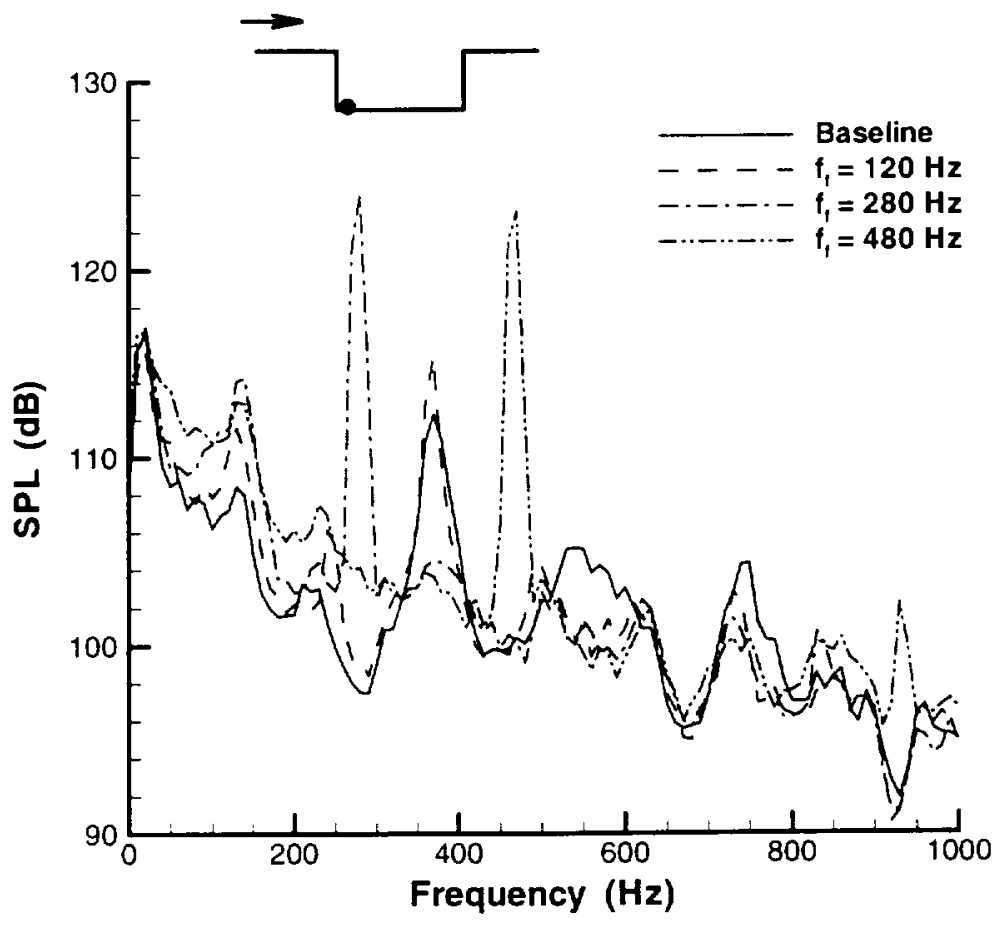

(b)

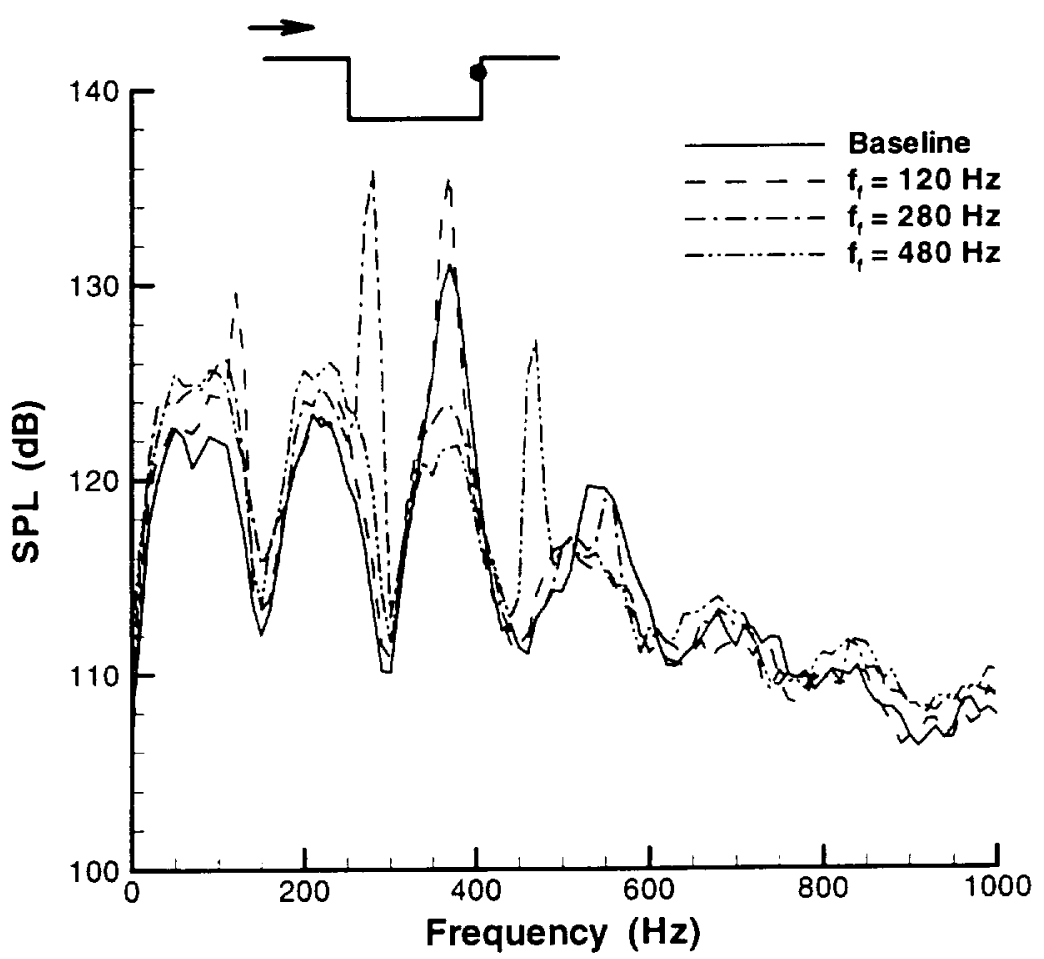

Figure 16: Spectra for oscillatory blowing, $\left\langle c_{\mu}>=0.0008\right.$.

(a) Floor (b) Rear wall locations. 
(a)

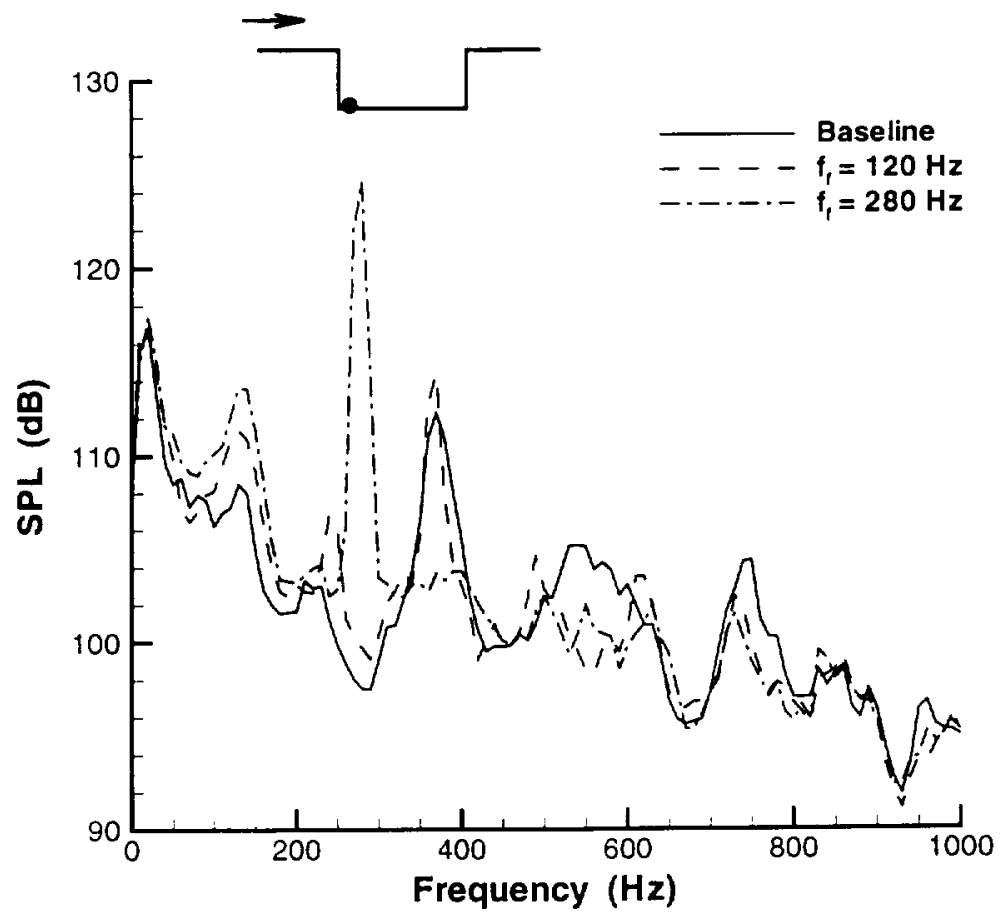

(b)

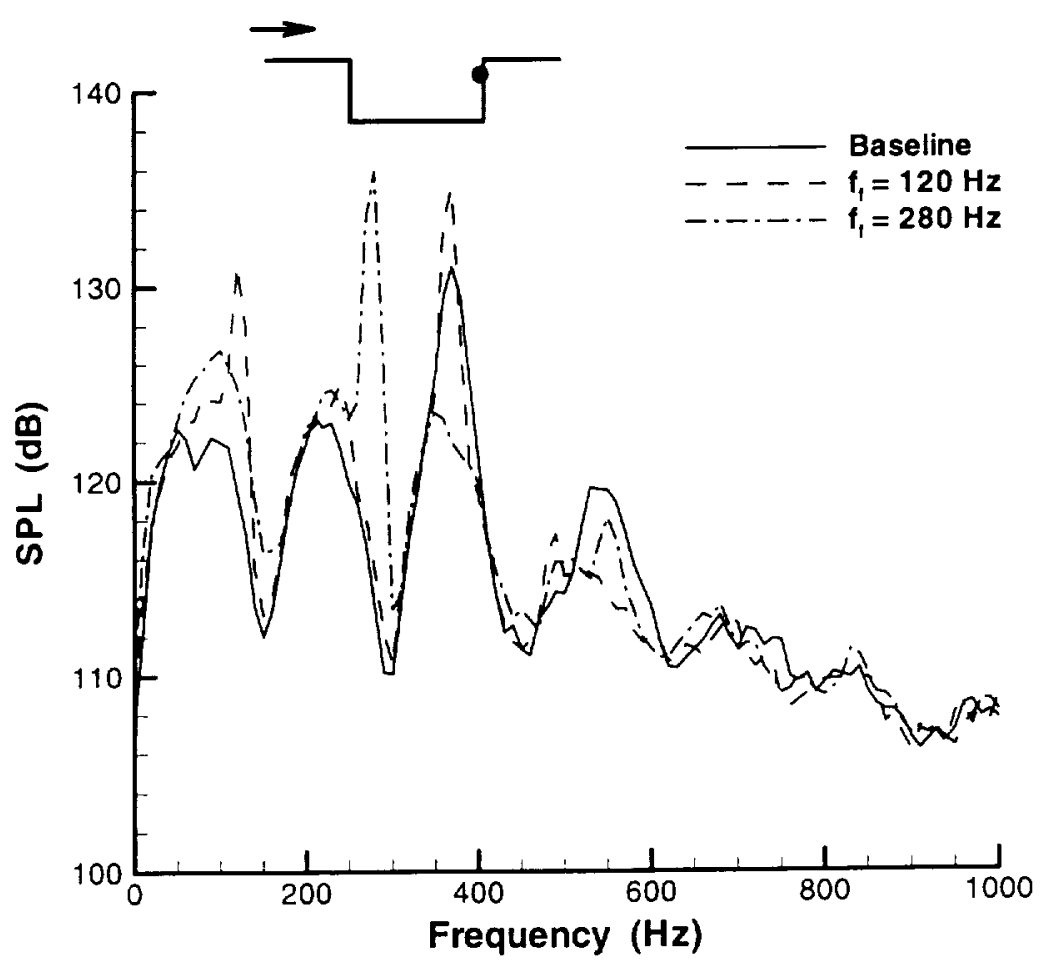

Figure 17: Spectra for oscillatory blowing, $<c_{\mu}>=0.0013$.

(a) Floor (b) Rear wall locations. 


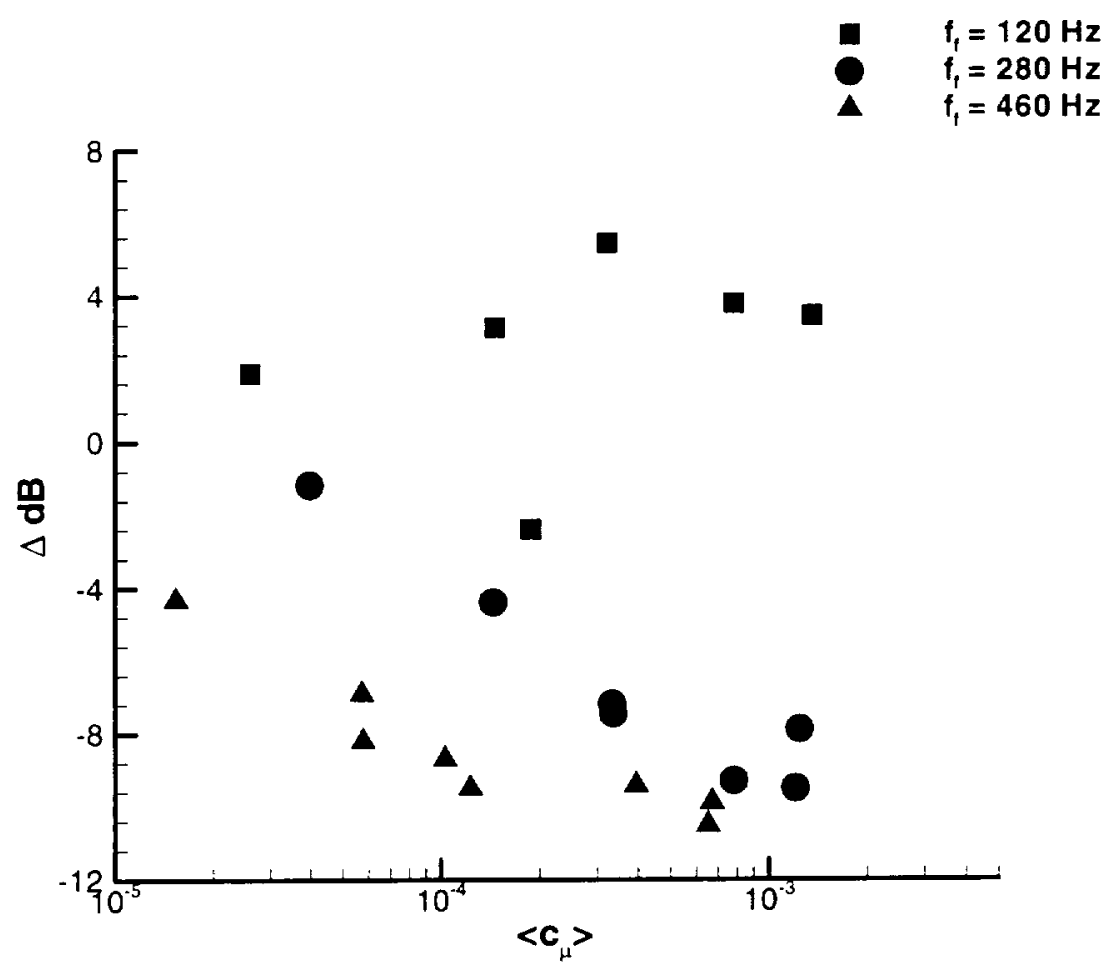

Figure 18: SPL reduction at $370 \mathrm{~Hz}$ for the rear wall location. 


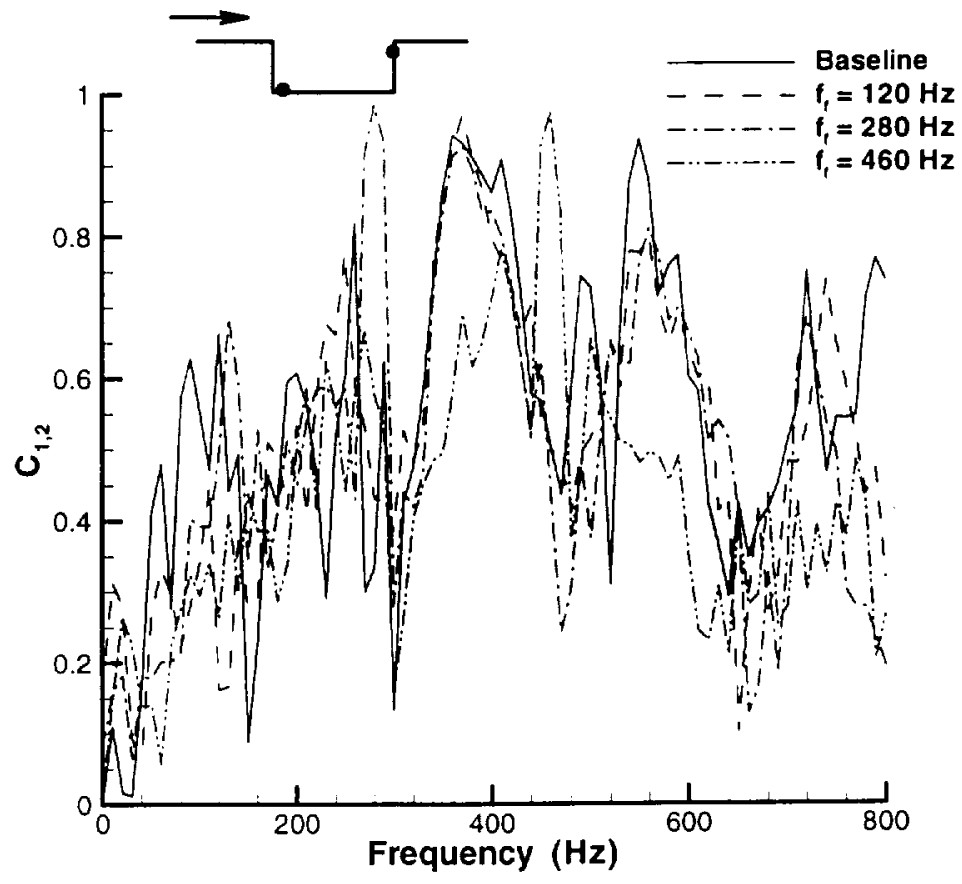

Figure 19a: Coherence between front and rear wall locations: oscillatory blowing, $\left\langle c_{\mu}>=0.0002\right.$.

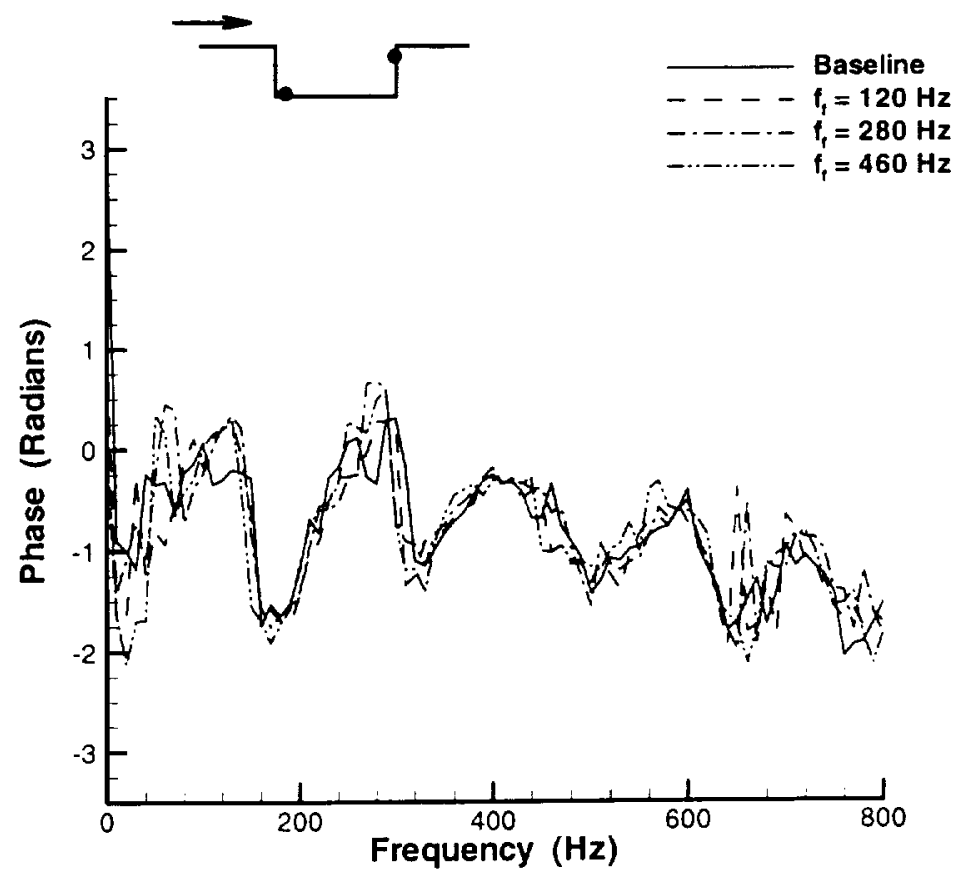

Figure 19b: Phase between front and rear wall locations: oscillatory blowing, $<\mathbf{c}_{\mu}>=0.0002$. 


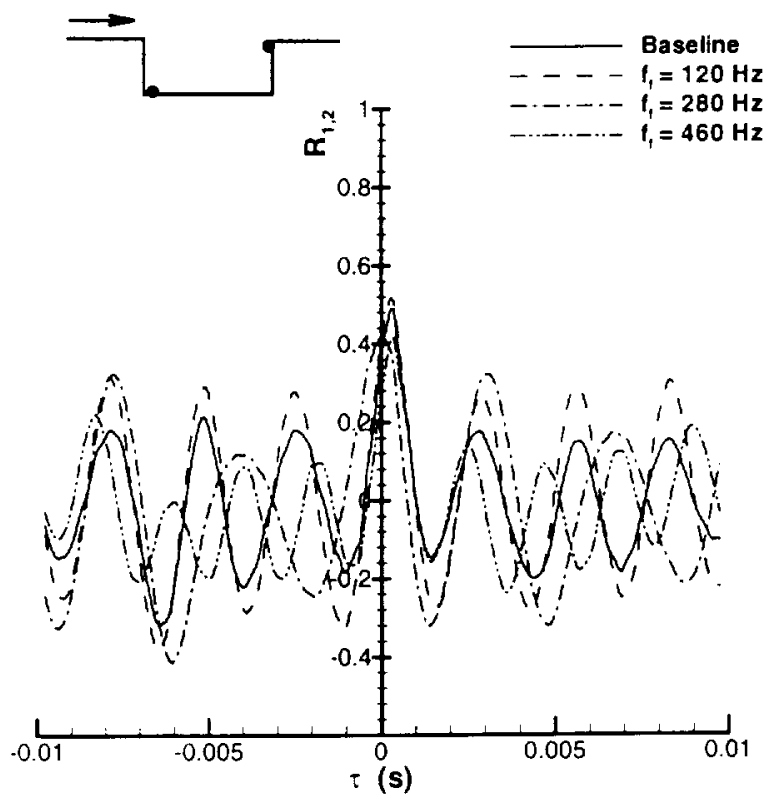

Figure 20: Cross-correlation between front and rear wall locations: oscillatory blowing, $\left\langle c_{\mu}\right\rangle=0.0002$.

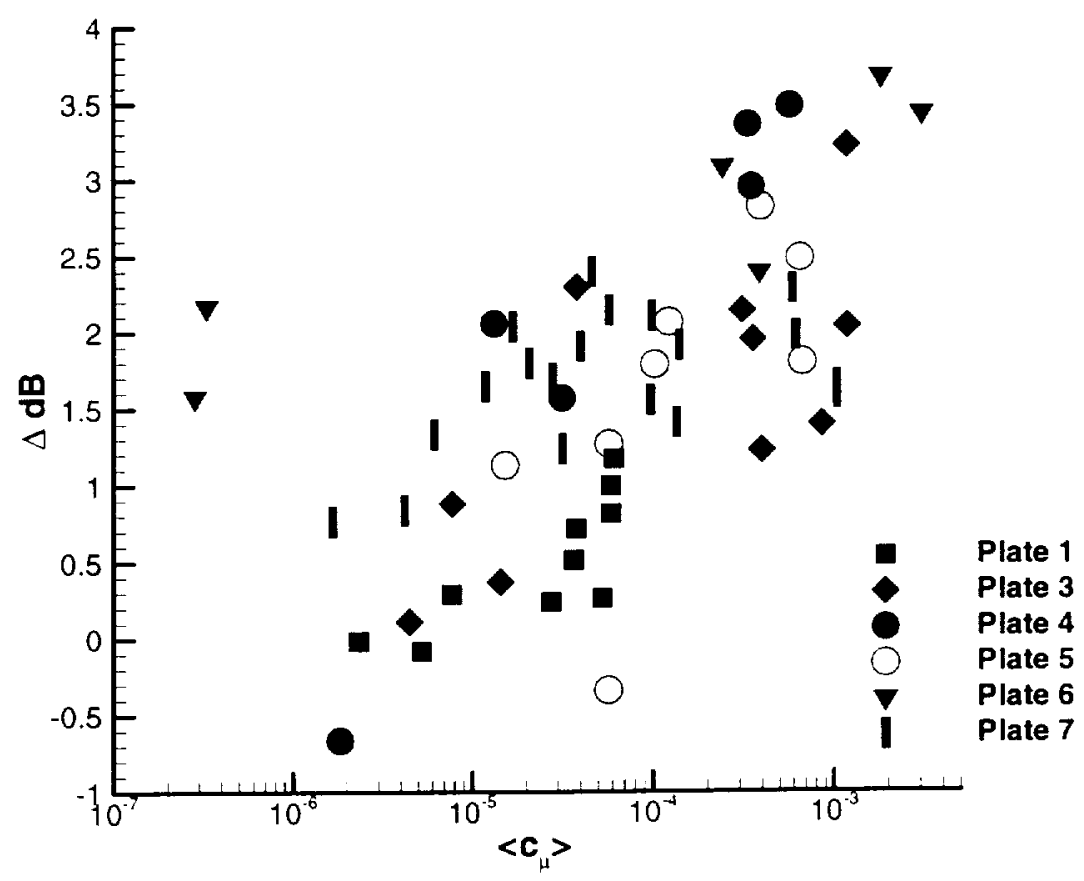

Figure 21: SPL reduction at $150 \mathrm{~Hz}$ for the rear wall location. $\mathrm{f}_{\mathrm{f}}=460 \mathrm{~Hz}$. 


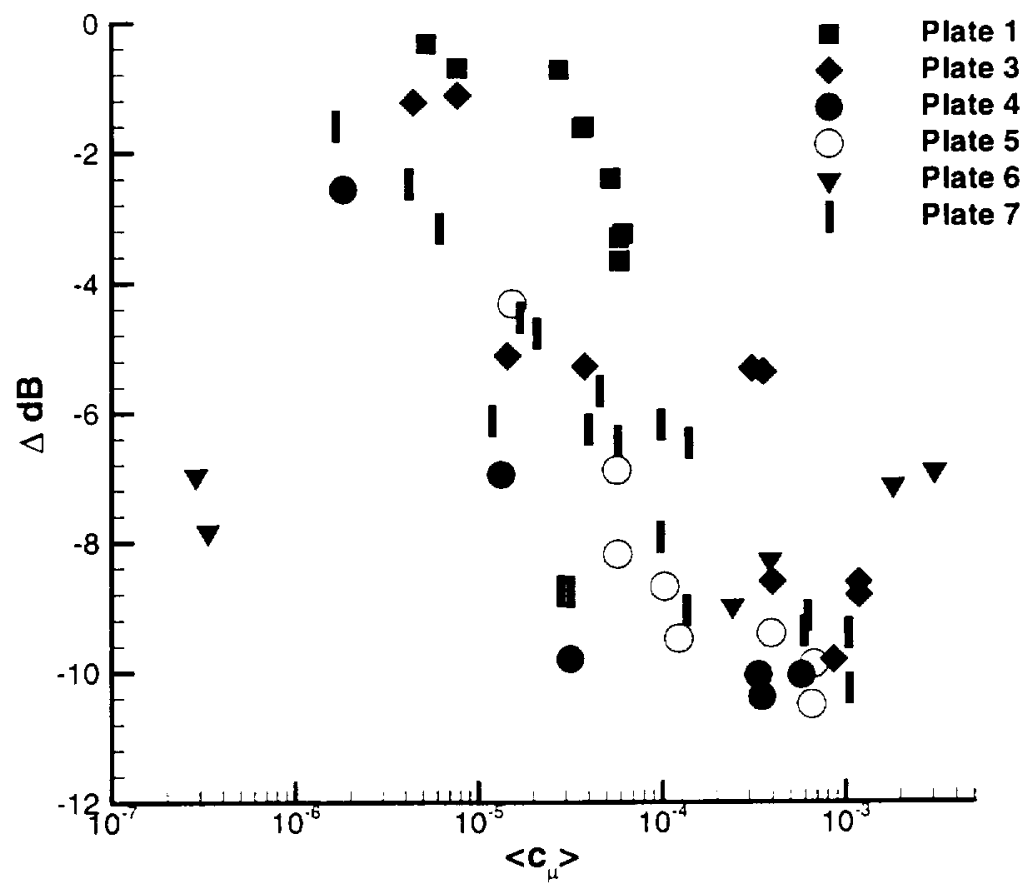

Figure 22: $S P L$ reduction at $370 \mathrm{~Hz}$ for the rear wall location. $f_{\mathrm{f}}=460 \mathrm{~Hz}$.

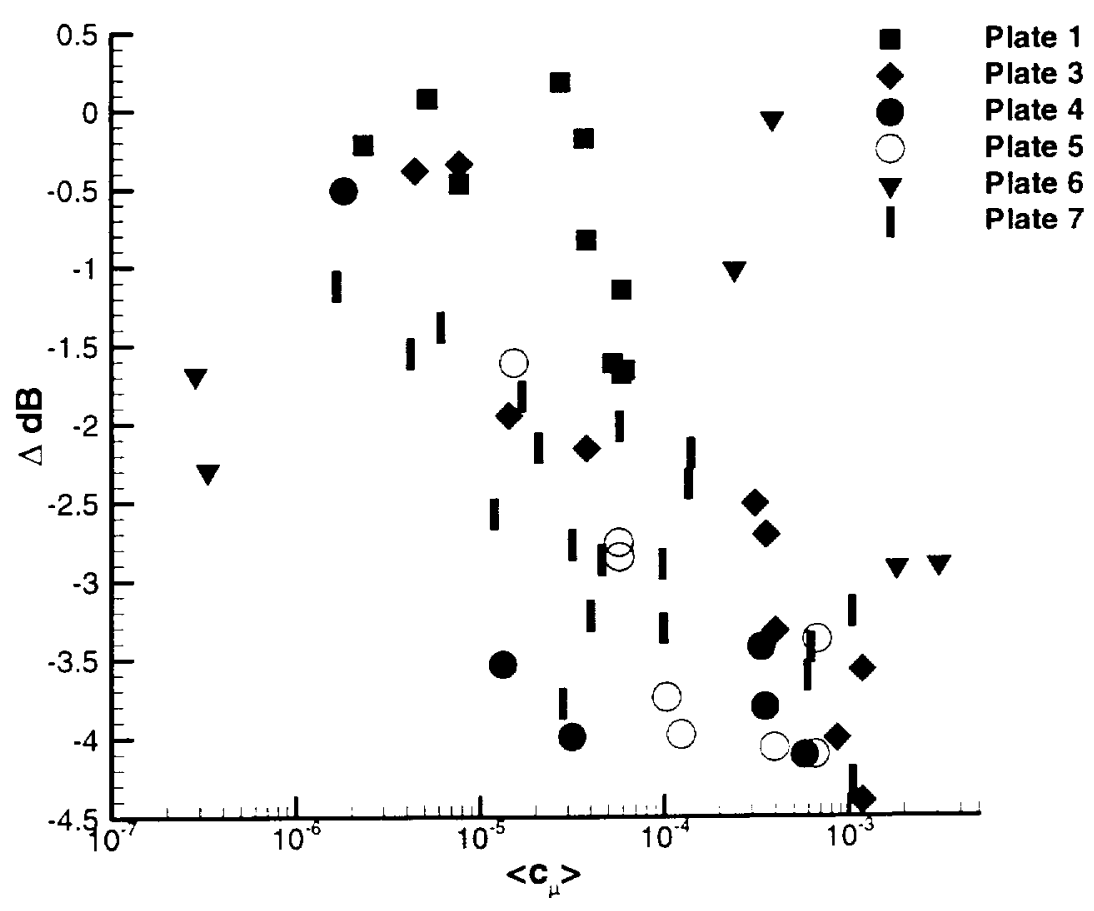

Figure 23: SPL reduction at $540 \mathrm{~Hz}$ for the rear wall location. $\mathrm{f}_{\mathrm{f}}=460 \mathrm{~Hz}$. 


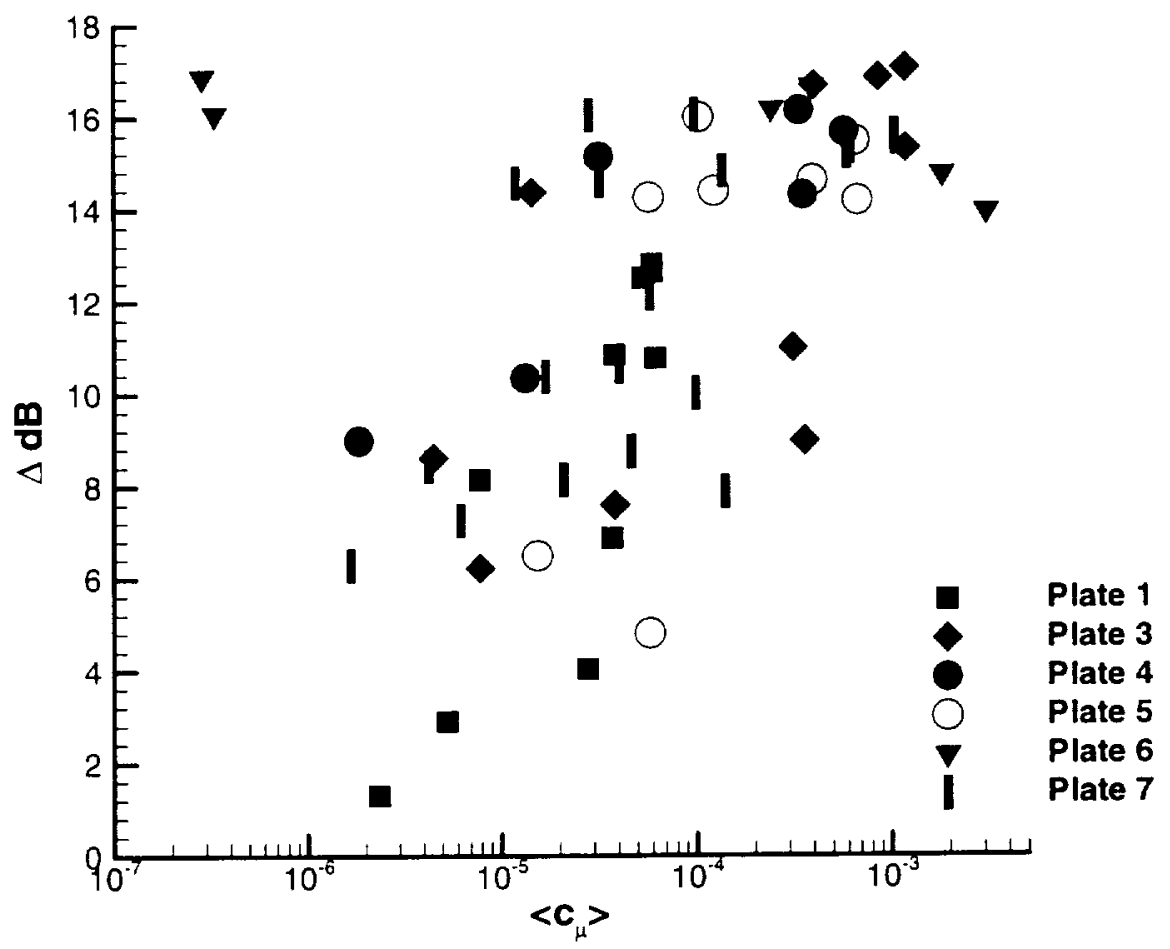

Figure 24: SPL reduction at $460 \mathrm{~Hz}$ for the rear wall location. $\mathrm{f}_{\mathrm{f}}=460 \mathrm{~Hz}$. 